\title{
EVALUATION OF TRANSITION CURVES ON TWO-LANE RURAL HIGHWAYS
}

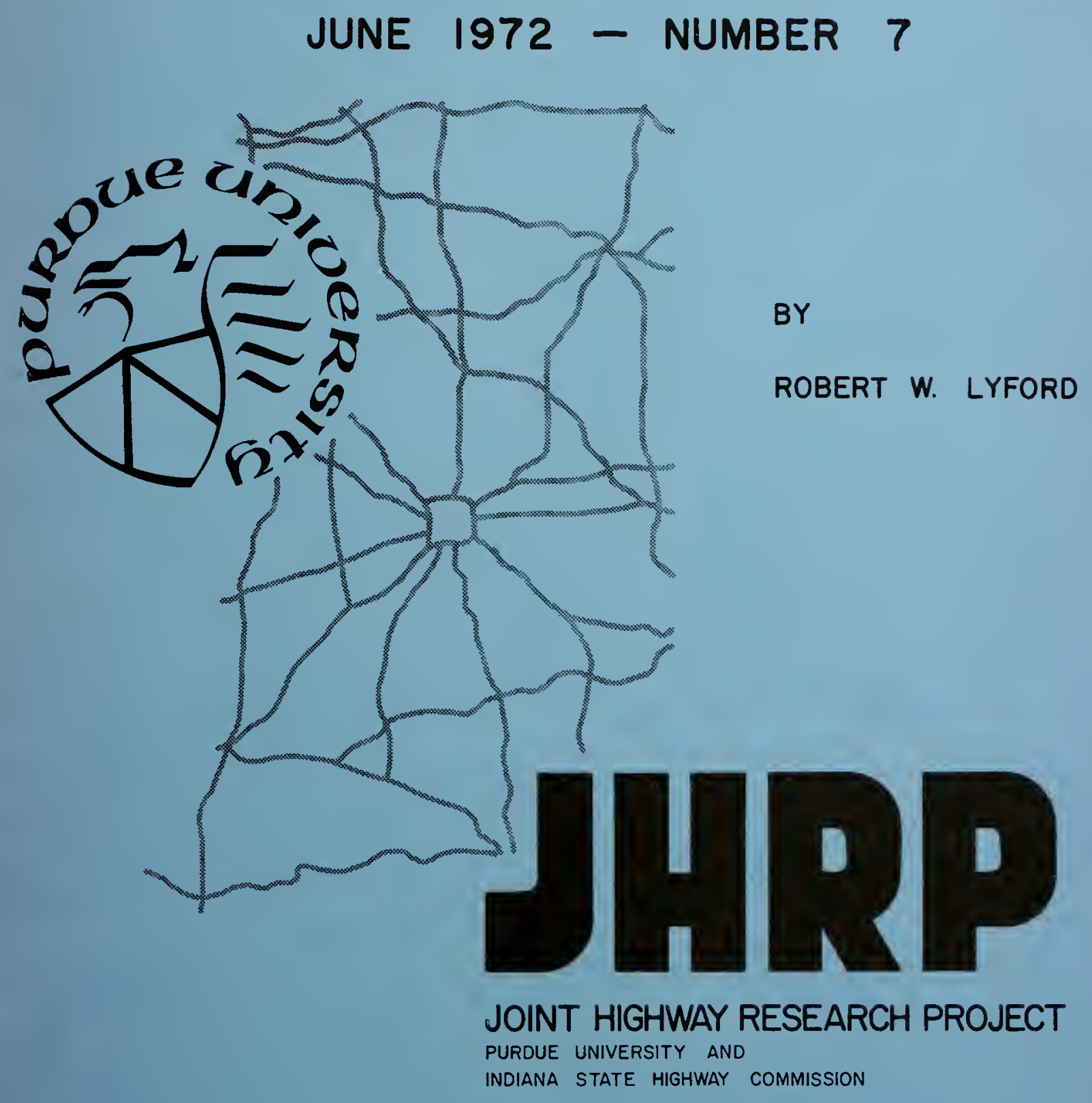





\section{Final Report}

EVALUATION OF TRANSITION CURVES ON TWO-LANE RURAL HIGHWAYS

TO: J.F. McLaughlin, Director Joint Highway Research Project

FROM: H. L. Michael, Associate Director Joint Highway Research Project
June 22, 1972

Project: C-36-68B

File: $\quad 3-6-2$

The attached Final Report is submitted on the JHRP research study titled "Evaluation of Transition Curves on Two-Lane, Rural Highways". The research and report was produced by Mr. Robert W. Lyford, Graduate Assistant in Research on our staff under the direction of Professors J. C. Oppenlander and H. L. Michael.

This study was proposed and approved in 1968. The delay in completion of this study resulted from a 2 -year interruption for the principal investigator while he served in the $U$. $S$. Army.

The primary finding that vehicles were found to follow non-spiraled curves of the three to five degree range with a more constant lateral placement than they do a spiraled curve should be of interest to the ISHC as it uses non-spiraled curves. The finding should be of value to the highway design field.

The report is presented as acceptance of the fulfillment of the objectives of the study.

Respectfully submitted,

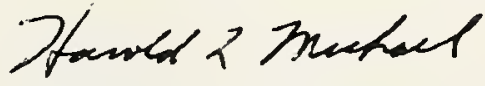

Harold L. Michael

Associate Director

HLM : ms
CC: W. L. Dolch
R. L. Eskew
W. H. Goetz
W. L. Grecco
M. J. Gutzwiller
G. K. Hallock

M. E. Harr

R. H. Harrell

M. L. Hayes

R. D. Miles

J. W. Miller

C. F. Scholer
M. B. Scott

J. A. Spooner

N. W. Steinkamp

H. R. J. Walsh

K. B. Woods

E. J. Yoder 


\title{
Final Report \\ EVALUATION OF TRANSITION CURVES ON TWO-LANE RURAL HIGHWAYS
}

\author{
by \\ Robert W. Lyford \\ Graduate Assistant in Research
}

Joint Highway Research Project

Project No.: C-36-68B

File No.: $3-6-2$

Purdue University

Lafayette, Indiana

June 22,1972 


\section{ACKNOWLEDGMENTS}

The author wishes to express his appreciation to Professor Joseph C. Oppenlander for his assistance and encouragement during the study and nis review of the manuscript. Appreciation is also expressed to Professors Virgil L. Anderson and Harold L. Michael for their review of the manuscript, and to Professor Gilbert T. Satterly for his review of the manuscript.

Thanks are also extended to Salim S. Hejal and Joe Dan Austin for their assistance in the formulation and analysis of the mathematical model.

The author extends special thanks to his wife for her assistance in typing the rough drafts and her patience during the course of this study. 
Digitized by the Internet Archive in 2011 with funding from

LYRASIS members and Sloan Foundation; Indiana Department of Transportation 
TABLE OF CONTENTS

Page

LIST OF TABLES...................... iv

LIST OF FIGURES ................... v

ABSTRACT ............................. vi

INTRODUCTION...................... I

REVIEW OF LITERATURE.................. 4

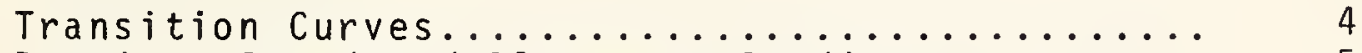

Previous Speed and Placement Studies............ 5

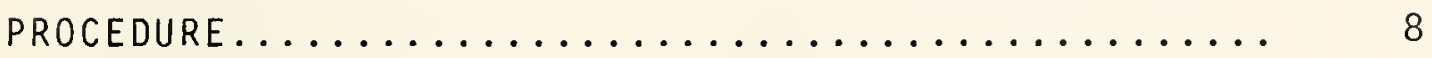

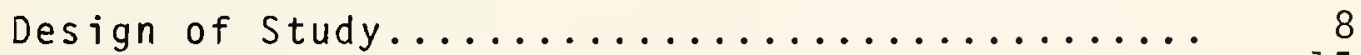

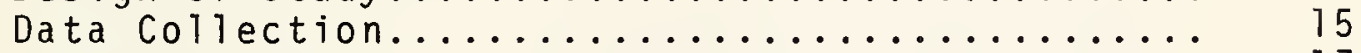

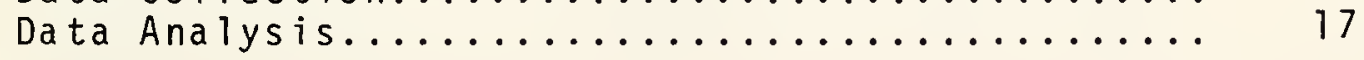

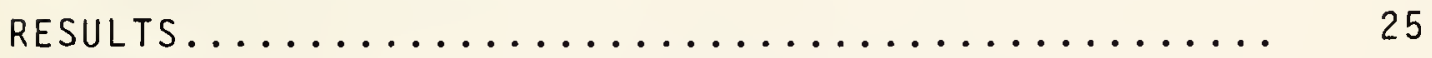

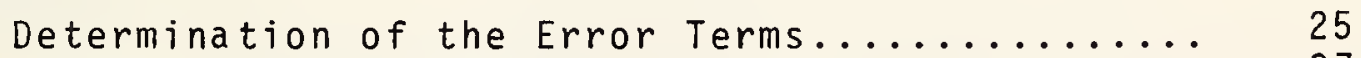

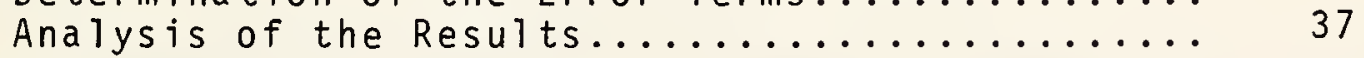

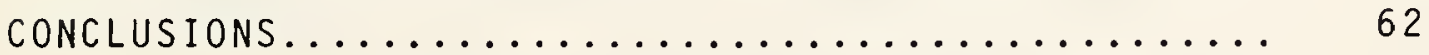

SUGGESTIONS FOR FURTHER RESEARCH............ 63

BIBLIOGRAPHY ........................ 65

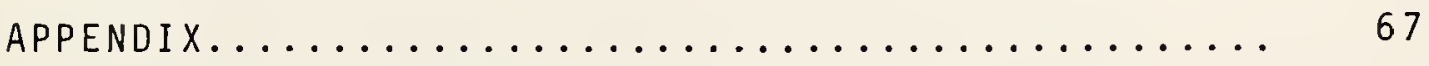

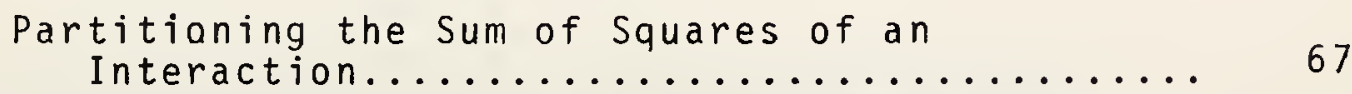


LIST OF TABLES

Table

Page

1. Summary Characteristics of the Evaluated

Curve Groups........................ is

2. Analysis of Variance.................. 26

3. Revised Analys is of Variance with Significance

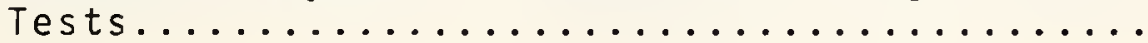

4. Analysis of Variance for the Whole Plot Level

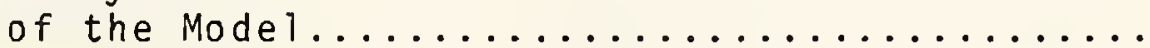

5. Analysis of Variance for the First Split-plot

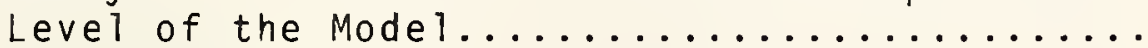

6. Analysis of Variance for the Second Split-Plot Level of the Model...................

7. Analysis of Variance for the Third Split-Plot Level of the Model...................

Appendix

Table

A1. Calculation of the Sum of Squares of the

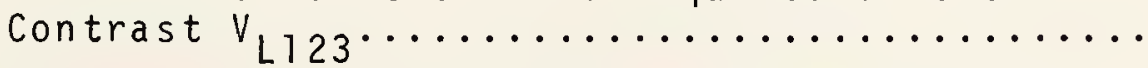

A2. Calculation of the Orthogonal Coefficients for Determining the Sum of Squares of the Contrast SV 123 .

A3. Calculation of the Sum of Squares of the Contrast SVL123.

A4. Calculation of the Orthogonal Coefficients for Determining the Sum of Squares of the Contrast SV $L 123^{P} \mathrm{AC}$.

A5. Calculation of the Sum of Squares of the

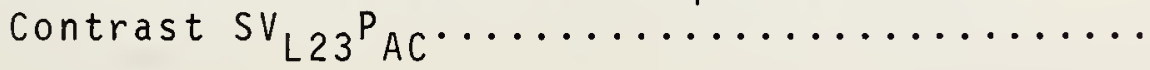


LIST OF FIGURES

Figure

Page

1. Partial Logic Diagram of the Data Evaluation... 10

2. Curve Positions and Stations for Measurement

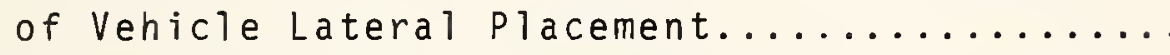

3. Hypothetical Form of the Expected Interaction of Degree of Curve with Type of Curve.........

4. Average Placement of Vehicles for Each Curve

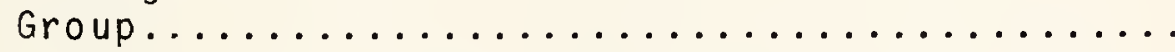

5. Effect of the Interaction of Curve Type with the First Three Curve Groups on Lateral

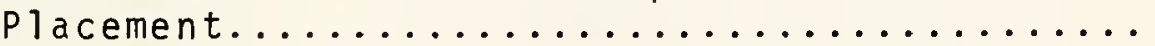

6. Effect of the Interaction of Curve Type with the First Three Curve Groups with Curve Positions $A$ and $C$ on Lateral Placement...........

7. Effect of the Interaction of Curve Type with the First Three Curve Groups with Curve Posi-

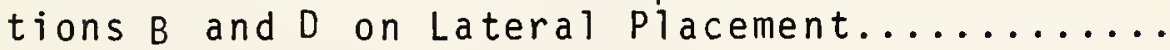

8. Effect of the Interaction of Vehicle Type with

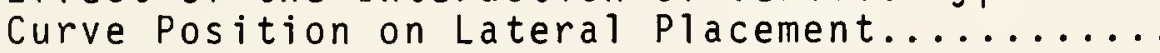

9. Effect of the Station of Measurement on Lateral Placement.

10. Effect of the Interaction of Station of Measurement with Curve Type on Lateral

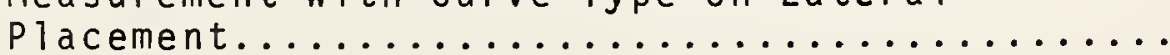

11. Effect of the Interaction of Station of Measurement with Curve Group on Lateral

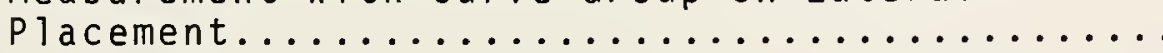

12. Effect of the Interaction of Station of Measurement with Curve Position on Lateral

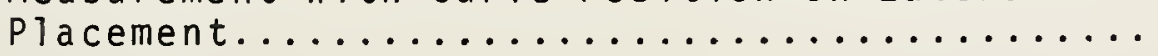




\section{LIST OF FIGURES (continued)}

Figure

Page

13. Effect of the Interaction of Curve Type with Vehicle Type on Lateral Placement....... 
ABSTRACT

Lyford, Robert Walter. M.S.C.E., Purdue University, June 1972. EVALUATION OF TRANSITION CURVES ON TWO-LANE, RURAL HIGHWAYS. Major Professors: Harold L. Michael and Joseph C. Oppenlander.

The purpose of this study was to determine the feasibility of transition curves in horizontal alinement, as measured by changes in vehicle placement on a curve. The movement of vehicles through both spiraled and unspiraled curves was analyzed to test the hypothesis that these curves cause similar changes in lateral placement of the vehicles.

The study showed that the paths of vehicles are affected by the use of spirals on horizontal curves. Vehicles were found to traverse a non-spiraled curve with a more constant lateral placement from the centerline than they did a spiraled curve.

other major findings of the study for both spiraled and non-spiraled curves were (a) truck combinations travel further from the centerline on a horizontal curve than do automobiles or single unit trucks, (b) the paths of vehicles relative to the roadway centerline are different for entering and leaving a curve and for the inside and outside of the curve, and (c) the degree of curve affects the lateral placement of the vehicle. 


\section{INTRODUCTION}

The continuing rise in traffic volumes and the desire for better operating characteristics on highways have recently prompted research interest in the geometric design of highways. Although geometric design relationships are developed from theoretical considerations, the determination of design values is greatly influenced by practical considerations. Present design practices have been developed over years of experience in an attempt to meet the needs and demands of highway traffic. However, differing design standards exist because of varying opinions on unquantified traffic flow situations. One difference exists in the application of transition curves in the design of horizontal al inement.

Engineers first used spirals on railroads to control the rate of change of lateral acceleration when a train enters or leaves a horizontal curve. Similar circumstances suggested the application of transition curves in the horizontal alinement of highways. As a driver enters or leaves a curve, some believe the natural tendency is to limit the rate of change of lateral acceleration within the limits of comfort and propose such an accomplishment by passing through a spiral curve in going from tangent to circular 
curve or from circular curve to tangent. The application of this principle resulted in the development of suitable transition curves for highways.

Because a highway vehicle is not constrained to a fixed path, it can easily make lateral shifts within its lane to follow either a circular or a spiral path. Many engineers, however, do not desire to complicate design calculations and field work by incorporating transition curves in the horizontal alinement. Other engineers feel that the transition curve helps the driver to enter and leave a horizontal curve by providing a more natural path to follow and permits the attainment of superelevation over the length of the spiral curve. As a result of these differences of opinion, about one-half of the states specify the inclusion of transition sections with horizontal curves (12)*. No reported study has been undertaken to ascertain the influence of spiral curves on traffic flow characteristics.

The purpose of this investigation was to determine the feasibility of transition curves in horizontal alinement as measured by changes in vehicle placement along the curve. The hypothesis that spiraled and unspiraled curves cause similar changes in lateral placement was tested to provide a recommendation on the use of transition sections in horizontal alinement. Other factors investigated in this study included the effect of type of vehicle using the curve,

* Numbers in parentheses refer to the 1 ist of references in the Bibliography. 
degree of the curve, and pavement width. With this information, highway design practices can be improved and refined to include only those design elements that are essential for the safe, efficient, economical, and comfortable movement of highway traffic. 


\section{REVIEW OF LITERATURE}

\section{Transition Curves}

Although a considerable amount of research has been conducted on the effects on traffic of various roadway elements, little discussion is evident in the literature on the effect of transition curves, and opinions vary on their usefulness and desirability in the selection and arrangement of the horizontal elements of highway design. The theoretical aspects of transition curves and their relation to vehicle behavior have been discussed in depth by J. Barnett. In his publication, tables are presented for the computation of spirals. These tables were developed from an analysis of vehicle speed, roadway superelevation, and friction between the pavement and vehicle tires. The use of spirals is predicted to result in greater safety, smoother riding, and a more graceful alinement of the highway than the use of simple curves only. However, no field verification was performed to substantiate these theoretical considerations (2).

The results of tests conducted on the Pennsylvania Turnpike indicated that spirals incorporated on sharp curves aided drivers in negotiating these curves. However, no specific conclusions about the effects of the spirals could 
be drawn because the tests were conducted at high speeds by a highly skilled driver experienced in high speed operation on curves $(16)$.

At least two papers promote the use of spirals to eliminate the sharp visual change in direction often caused by the change from tangent to curve, thereby making curves more aesthetically pleasing $(13,15)$. The American Association of State Highway Officials recommends the design of highways with built-in safety, and this recommendation includes the use of transition curves for the horizontal alinement. The advantages of highway curvature with spirals are listed as an easy-to-follow path for drivers, a convenient arrangement for superelevation runoff, and enhancement of the highway appearance. On the other hand, AASHO recognizes that with moderate speed and curvature a driver can perform a transition within the width of the normal traffic lane (12).

\section{Previous Speed and Placement Studies}

Many articles have been written on vehicular speeds and placements in both urban and rural areas. The Highway Users Federation for Safety and Mobility has published a series of annotated bibliographies on various aspects of highway safety, including speed and alinement as specific topics (8). Other articles have also been written. Included here are brief reviews of articles pertaining specifically to speed and placement as related to spiral and 
curve design and the data collection design.

Speed and placement data have been collected in several ways. Detectors constructed of pneumatic tubes have been used many times for both speed and placement studies, but this method has been generally abandoned because of the effect of the road tubes on driver behavior. In attempts to eliminate the effects on drivers of their observance of data collection equipment and the operators, photographic methods have been employed. The use of photography often permits the data collection equipment and personnel to be hidden from view.

The concept of photographic data collection was introduced by B. D. Greenshields in a study of vehicular speeds (6). F. H. Green later refined the procedure to collect speed and placement data simultaneously. In his procedure Green photographed marking boards on the pavement at several measuring stations. The boards were then removed, and the vehicles were filmed as they passed through the study section. Images of the boards and vehicles were superimposed for reducing the data from the film (5).

Other authors have used modifications of Green's procedure to collect data on traffic behavior on various widths of roadway (11), at a narrow highway bridge (14), and at various other highway geometric features (20). P. Gray and $W$. Kauk photographed vehicles on loop ramps to determine vehicular speeds and lateral placements at various points 
on the ramps (4). Speeds, placements, and spacing of vehicles on expressways in Texas were determined photographically by C. J. Keese and R. H. Schleider (9).

A. Taragin reached several conclusions about the performance of drivers on horizontal curves. His most important conclusions were that (a) drivers make most speed changes before entering a horizcntal curve, (b) the amount of superelevation on curves does not affect vehicle speeds, and (c) speed and curvature are related linearly by the following equation:

Average Speed $=46.26-0.746 \times$ Degree of Curve (18).

In another study, Taragin found that vehicle speeds did not appear to be affected by shoulder width and type, but, on roads with fully-paved shoulders, the placement from the centerline of slower vehicles was greater than the placement of faster vehicles by as much as two feet. No relation between placement and speed was observed on roads with gravel or grass shoulders (17).

Almost no research has been performed on the effects of spiral curves on driver behavior. The use of these curves is based almost entirely on engineering judgment and theoretical considerations. This paper investigates the travel path of vehicles on spiraled and unspiraled curves. 


\section{PROCEDURE}

\section{Design of Study}

To reaijze the objective of this research investigation. data were obtained on the movement of vehicies through the two types of horizontal curve arrangenents. Variations in the paths of vehicles in each travei direction at each end of the horizontal curve were investigated by measuring the lateral placement of the vehicies at pre-determined intervals along the circular curve and along the sections at each end of the curve. The degree of curve and width of pavement were also measured as input parameters. Vehicles were classified into the three groups of passenger vehicle, single-unit truck, and truck combination. Pessenger venicles with trailers and oversize vehicles were not considered in this analysis of traffic-flow characteristics.

The field measurements were obtained in a manner that would not affect driver behavior. Because data were required at several piaces near the ends of each curve, all methods of data recording except photography were considered as likely to affect driver behavior. A filming procedure described by F. H. Green was used with some modifications in this study (5). 
With the use of the photographic method, the number of stations that could be evaluated was somewhat limited. Because the actual distance required for a vehicle to change movement from a straight 1 ine to a circular curve was not known, a pilot study was conducted to determine the visbility range and the resolution of the photographic equipment and to test the data collection procedure. In this pilot study, the data were best collected over a 500-ft section, with measurements of lateral placement taken in $0.5-\mathrm{ft}$ increments at stations spaced every $50 \mathrm{ft}$. These stations were set according to the following criteria. For unspiraled curve ends, the stations were divided evenly between the tangent and circular curve with one station on the point of tangency. The spiraled curve ends included the length of spiral with excess stations divided as evenly as possible between the tangent and the circular portion of the curve. One station was located on the point of change from tangent to spiral.

The design of this experiment is illustrated by the partial logic diagram in Figure 1. Both types of curve, spiraled and unspiraled, were studied for four curve groups, which are identified as $1,2,3$, and 4 in Figure 1. Each spiraled curve group is comparable to the same numbered unspiraled curve group with respect to degree of curve and width of pavement. All curves have the four curve positions, identified as $A$, 

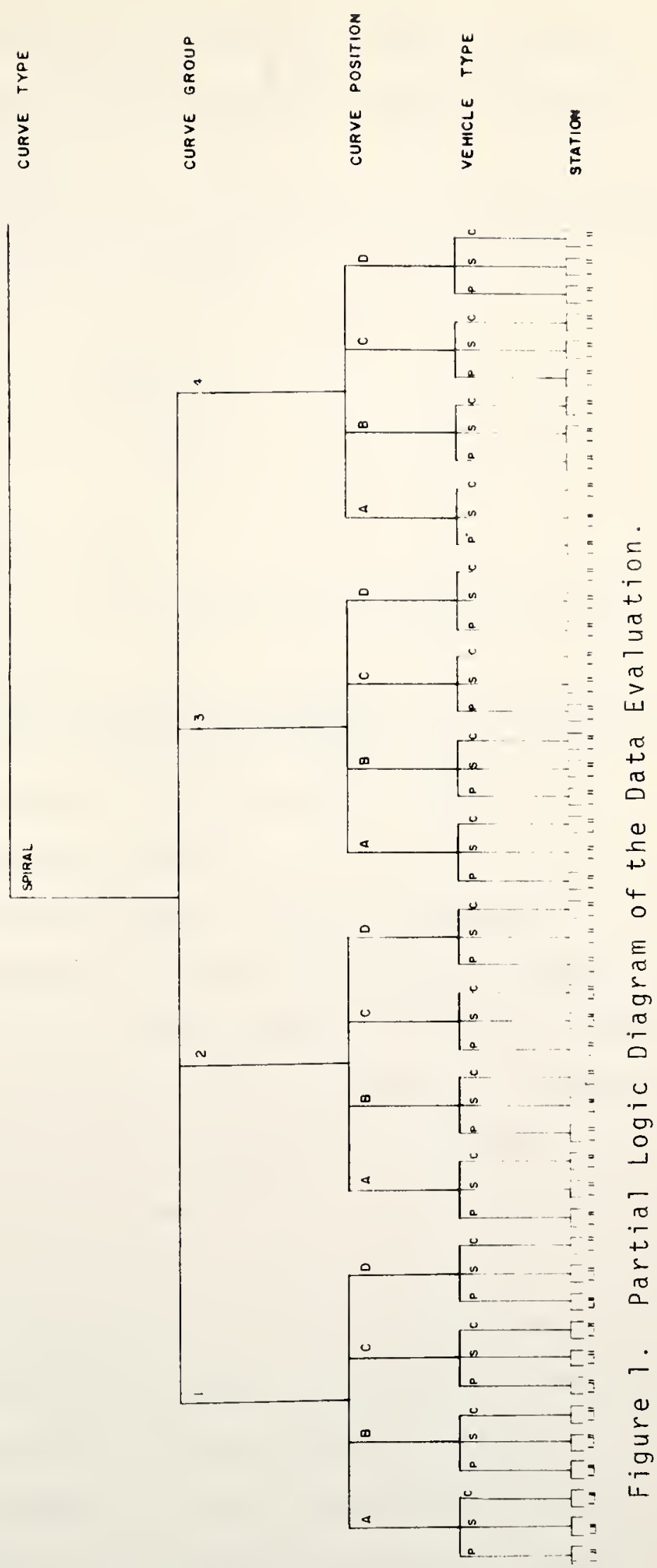
$B, C$, and $D$, and the eleven stations as shown in Figure 2 . Measurements were taken on each type of vehicle at each of the established stations.

For a normal distribution, sample size was determined according to the following equation:

$$
n=\frac{z_{\alpha / 2}^{2} s^{2}}{E^{2}}
$$

where

$$
\begin{aligned}
& n= \\
Z= & \text { normal deviate corresponding to the desired level } \\
& \text { of significance, } \\
\alpha= & \text { level of significance; and implied is } B=\text { probabil- } \\
& \text { ity of accepting hypothesis when it is false }=.5, \\
S= & \text { standard deviation of the sample and, } \\
E= & \text { maximum tolerable error. }
\end{aligned}
$$

Data collected on the variations in lateral placement during the pilot study had a standard deviation of about $0.9 \mathrm{ft}$. To have the sample mean within $0.5 \mathrm{ft}$ of the true mean at $\alpha=.10$ significance level, observations of nine vehicles were required at each location. Therefore, ten measurements of lateral placement were taken of each vehicle type at each station in each curve position. Because Indiana does not use transition curves, two bordering states which use spirals, Ohio and Kentucky, were canvassed for horizontal curves which would satisfy the experimental design.

A primary requirement for curve selection was the presence of an embankment or hill near the curve with features, 


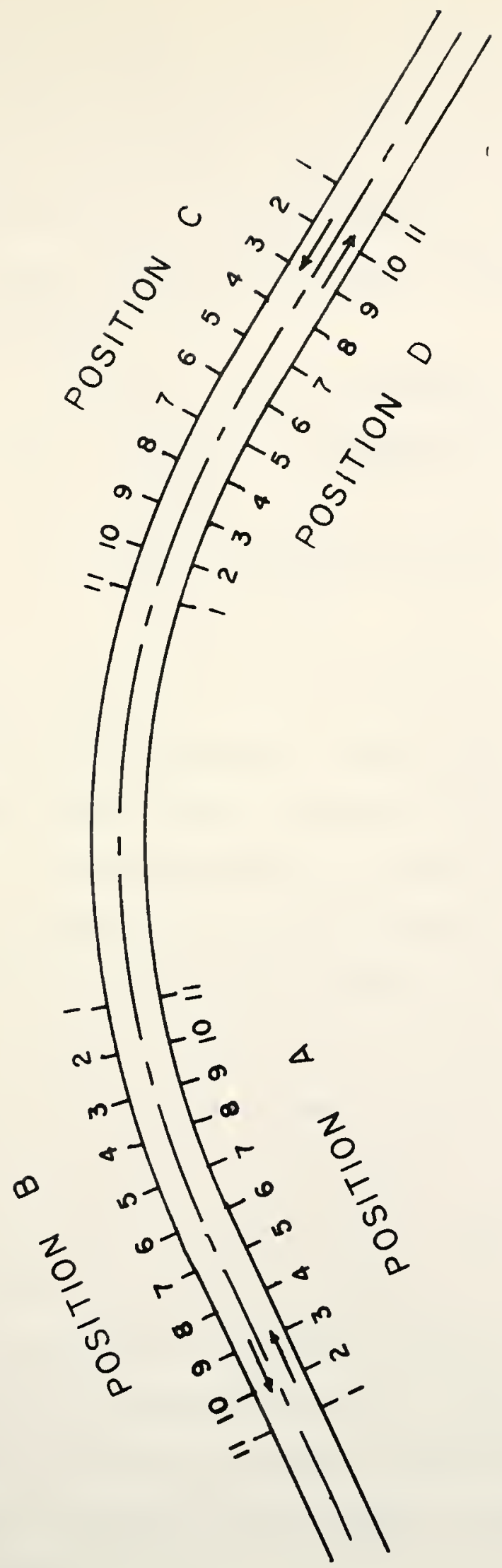

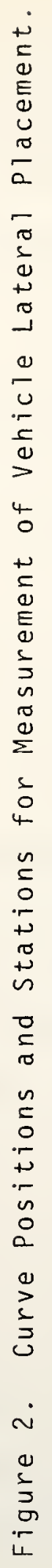


such as trees or signs, to shield the camera and operator. A location above the level of the highway allowed the surface of the 500-ft study sections to be photographed at an obtuse angle. Other geometrics were kept as constant as possible in the selection of study sites. The conditions included:

1. Rural, two-lane highways,

2. No major intersections within $1000 \mathrm{ft}$ of the study section,

3. Grades 1ess than 1 percent within 1000 ft of the study location, and

4. Simple curves.

Only highways with sufficient traffic volumes to make data collection expedient were investigated, and all observations were taken in good weather during the Fall of 1968 .

Finding horizontal curves with the necessary geometric characteristics was difficult to achieve. The characteristics of the curves selected for data collection are summarized in Table 1. Spiraled and unspiraled curves with equal degrees of curvature were found for Group 1 only. However, for purposes of this analysis, the two curves in each curve group were assumed to have similar curvature characteristics. Because the length of spiral is based on both the degree of curvature and the design speed, no correlation between degree of curve and length of spiral is evident in Table 1. No spiraled curves with greater than 4.5 deg of curvature were located because modern highways are designed with gentle curves. 
Table 1. Summary Characteristics of the Evaluated Curve Groups.

\begin{tabular}{ccccc}
\hline $\begin{array}{c}\text { Curve } \\
\text { Group }\end{array}$ & $\begin{array}{c}\text { Transition } \\
\text { Curve }\end{array}$ & $\begin{array}{c}\text { Degree } \\
\text { of } \\
\text { Curve }\end{array}$ & $\begin{array}{c}\text { Length } \\
\text { of } \\
\text { Spiral }\end{array}$ & $\begin{array}{c}\text { Pavement } \\
\text { Width }\end{array}$ \\
\hline 1 & Yes & 3 & $400 \mathrm{ft}$. & $24 \mathrm{ft}$. \\
No & 3 & - & $24 \mathrm{ft}$. \\
2 & Yes & $3-1 / 2$ & $200 \mathrm{ft}$. & $24 \mathrm{ft}$. \\
& No & 4 & - & $24 \mathrm{ft}$. \\
3 & Yes & $4-1 / 2$ & $250 \mathrm{ft}$. & $24 \mathrm{ft}$. \\
& No & 5 & - & $24 \mathrm{ft}$. \\
4 & Yes & 3 & $180 \mathrm{ft}$. & $22 \mathrm{ft}$. \\
& No & 2 & - & $22 \mathrm{ft}$.
\end{tabular}


Only free-flowing vehicles, selected by criteria set forth by A. Taragin, were analyzed in this investigation. A vehicle was considered free moving if it crossed a station 6 sec or more behind a vehicle traveling in its lane and 10 sec before and $5 \mathrm{sec}$ after a vehicle traveling in the opposite direction (19). These times were estimated in the field and verified from an analysis of the photographs.

Because the collection and reduction of the data in a completely randomized fashion was impractical due to the large amount of information, these processes were simplified by collecting the data in a manner which placed restrictions on the randomization. The combination of curve type and curve group was first chosen. The four curve positions were then sampled within the curve, the three vehicle types were recorded for the curve position, and the measurements were taken at each station for the free-flowing vehicles. This data collection was repeated at each station for ten vehicles of each type on each curve position of the chosen curve.

This data collection procedure was repeated for each combination of curve type and curve group. The restrictions on the complete randomization of the experiment were represented mathematically by a split-plot type design. This design will be explained in the description of the data analysis.

\section{Data Collection}

The collection of the data consisted of photographing the vehicles and of reducing the data from the movie films. 
In the field procedure the camera was positioned so that the eleven stations could be filmed with the camera and operator screened as much as possible from the view of approaching drivers. Pneumatic tubes were set transversely on the pavement at each station throughout the 500-ft study section, photographed, and removed. Without moving the camera, the vehicles were filmed passing through the study section. Vehicles which satisfied the requirements of freemoving vehicles were photographed until the required number of vehicles of each class was obtained.

A stop-motion projector was used for analyzing the films. The marking tubes were first projected on paper affixed to a wall. Then, the tubes were traced as lines on the paper, and other prominent features were outlined for reference. The lines were then evenly subdivided to represent 1-ft marks across the width of the pavement. Then, the film was advanced until the near wheels of the first vehicle crossed the first station. The front wheels of approaching vehicles and the rear wheels of departing vehicles were used for this reference. The effect of non-tracking of the rear wheels was ignored because of the gentle curves that were evaluated in this field study.

When the wheels were at the first station, on either entering or leaving the curve, the frame counter on the projector was set to zero, and the vehicle type and the placement from the roadway centerline of the outside of the 
inner wheel were recorded. The film was then advanced until the wheels were on the second station, and the frame number and lateral placement were again observed. This data recording procedure was repeated for each vehicle at each station until the vehicle had reached the end of the study section.

The headways of vehicles traveling in the same direction were determined by not resetting the frame counter when a following vehicle was observed. The number of frames between vehicles at each station was divided by the camera speed of 16 frames per second to compute the headway value in seconds. Any vehicle traveling less than $6 \mathrm{sec}$ behind another vehicle was not considered to be free-flowing. The meeting times of vehicles in opposite lanes were determined in a similar manner, and the 10-sec before and 5-sec after criteria for meeting opposing traffic provided the other minimum definition of free-flowing conditions.

\section{Data Analysis}

The data analysis was performed as a split-plot type design with the model represented in the following mathematical form (1): 


$$
\begin{aligned}
Y_{i j k l m n}=\mu & +S_{i}+V_{j}+S V_{i j}+\delta(i j) \\
& +P_{k}+S P_{i k}+V P_{j k}+S V P_{i j k}+w(i j k) \\
& +T_{1}+S T_{i 1}+V T_{j l}+S V T_{i j l}+P T_{k l}+S P T_{i k 1}+V P T_{j k 1} \\
& +S V P T_{i j k 1}+\eta(i j k 1) m \\
& +L_{n}+S L_{i n}+V L_{j n}+S V L_{i j n}+P L_{k n}+S P L_{i k n}+V P L_{j k n} \\
& +S V P L_{i j k n}+T L_{1 n}+S T L_{i l n}+V T L_{j l n}+S V T L_{i j l n} \\
& +P T L_{k l n}+S P T L_{i k l n}+V P T L_{j k l n}+S V P T L_{i j k 1 n} \\
& +n L_{I j k 1) m n}+\varepsilon_{(i j k 1 m n)}
\end{aligned}
$$

where

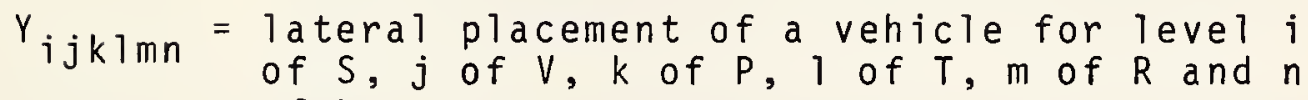

$$
\begin{aligned}
& \text { of } L \text {, } \\
& \mu=\text { overall mean of the lateral placement measure- } \\
& \text { ment, } \\
& S_{i}=\text { effect of spiraled versus unspiraled curves } \\
& \text { on the lateral placement of a vehicle, } \\
& v_{j} \quad=\text { effect of the } j \text { th level of curve group on the } \\
& \text { lateral placement of a vehicle, } \\
& S V_{i j}=\text { effect of the interaction of the } i \text { th curve } \\
& \text { type with the jth curve group on the lateral } \\
& \text { placement of a vehicle, } \\
& \delta_{i j}=\begin{array}{l}
\text { error due to the first restriction on random- } \\
\text { ization, }
\end{array} \\
& P_{k}=\text { effect of the kth level of curve position on } \\
& \text { the lateral placement of a vehicle, } \\
& S P_{i k}=\text { effect of the interaction of the } i \text { th curve } \\
& \text { type with the kth curve position on the } \\
& \text { lateral placement of a vehicle, }
\end{aligned}
$$




$$
\begin{aligned}
& V P_{j k} \quad=\text { effect of the interaction of the } j \text { th curve } \\
& \text { lateral placement of a vehicle, } \\
& \text { SVP }_{i j k}=\text { effect of the interaction of the } i \text { th curve } \\
& { }^{\omega}(i j k)=\begin{array}{l}
\text { error due to the second restriction on } \\
\text { randomization, }
\end{array} \\
& \begin{aligned}
T_{1} \quad= & \text { effect of the } 1 \text { th level of vehicle type on } \\
& \text { the lateral placement of a vehicle, }
\end{aligned} \\
& \text { ST }_{i 1}=\text { effect of the interaction of the ith curve } \\
& \text { type with the } 1 \text { th vehicle type on the } \\
& \text { lateral placement of a vehicle, } \\
& V T_{j 1} \quad=\text { effect of the interaction of the } j \text { th curve } \\
& \text { group with the } 1 \text { th vehicle type on the } \\
& \text { lateral placement of a vehcile, } \\
& \text { SVT }_{i j 1}=\text { effect of the interaction of the } i \text { th curve } \\
& \text { type with the jth curve group with the } 1 \text { th } \\
& \text { vehicle type on the lateral placement of a } \\
& \text { vehicle, } \\
& \text { PT } k 1=\text { effect of the interaction of the kth curve } \\
& \text { lateral placement of a vehicle, }
\end{aligned}
$$

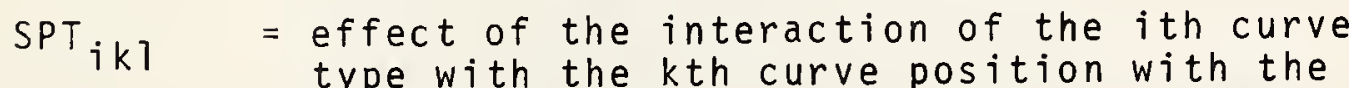

$$
\begin{aligned}
& \text { type with the kth curve position with the } \\
& 1 \text { th vehicle type on the lateral placement } \\
& \text { of a vehicle, } \\
& V T_{j k 1}=\text { effect of the interaction of the } j \text { th curve }
\end{aligned}
$$




\begin{tabular}{|c|c|}
\hline$n$ & $\begin{array}{l}=\text { effect of the nth level of station on the } \\
\text { lateral placement of a vehicle. }\end{array}$ \\
\hline in & $\begin{array}{l}=\text { effect of the interaction of the ith curve } \\
\text { type with the nth station on the lateral } \\
\text { placement of a vehicle. }\end{array}$ \\
\hline jn & $\begin{array}{l}=\text { effect of the interaction of the jth curve } \\
\text { group with the nth station on the lateral } \\
\text { placement of a vehicle. }\end{array}$ \\
\hline$L_{i j n}$ & $\begin{array}{l}=\text { effect of the interaction of the ith curve } \\
\text { type with the jth curve group with the nth } \\
\text { station on the lateral placement of a } \\
\text { vehicle, }\end{array}$ \\
\hline$P L_{k n}$ & $\begin{aligned}= & \text { effect of the interaction of the kth curve } \\
& \text { position with the nth station on the lateral } \\
& \text { placement of a vehicle, }\end{aligned}$ \\
\hline$S P L_{i k n}$ & $\begin{array}{l}=\text { effect of the interaction of the ith curve } \\
\text { type with the kth curve position with the } \\
\text { nth station on the lateral placement of a } \\
\text { vehicle, }\end{array}$ \\
\hline$V P L_{j k n}$ & $\begin{array}{l}=\text { effect of the interaction of the jth curve } \\
\text { group with the kth curve position with the } \\
\text { nth station on the lateral placement of a } \\
\text { vehicle, }\end{array}$ \\
\hline$S V P L_{i j k n}$ & $\begin{array}{l}=\text { effect of the interaction of the ith curve } \\
\text { type with the jth curve group with the kth } \\
\text { curve position with the nth station on the } \\
\text { lateral placement of a vehicle, }\end{array}$ \\
\hline$T_{1 n}$ & $\begin{array}{l}=\text { effect of the interaction of the lth vehicle } \\
\text { type with the nth station on the lateral } \\
\text { placement of a vehicle, }\end{array}$ \\
\hline$S T L_{i 1 n}$ & $\begin{array}{l}=\text { effect of the interaction of the ith curve } \\
\text { type with the lth vehicle type with the } \\
\text { nth station on the lateral placement of a } \\
\text { vehicle, }\end{array}$ \\
\hline$V T L_{j 1 n}$ & $\begin{array}{l}=\text { effect of the interaction of the jth curve } \\
\text { group with the lth vehicle type with the } \\
\text { nth station on the lateral placement of a } \\
\text { vehicle, }\end{array}$ \\
\hline SVTL $_{j}$ & $\begin{aligned} &= \text { effect of the interaction of the ith curve } \\
& \text { type with the jth curve group with the } 1 \text { th } \\
& \text { vehicle type with the nth station on the } \\
& \text { lateral placement of a vehicle, }\end{aligned}$ \\
\hline
\end{tabular}




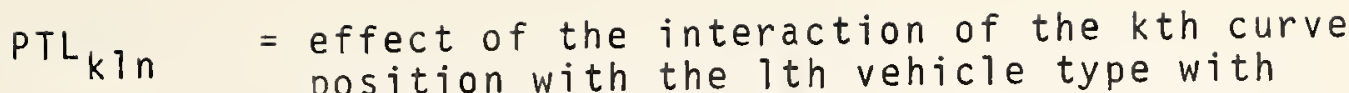
position with the ith vehicle type with the nth station on the lateral placement of a vehicle,

SPTL $i k 7 n=$ effect of the interaction of the $i$ th curve type with the kth curve position with the ith vehicle type with the nth station on the lateral placement of a vehicle,

VPTL jkln = effect of the interaction of the $j$ th curve group with the kth curve position with the ith vehicle type with the nth station on the lateral placement of a vehicle; SVPTL $_{i j k 1 n}=\begin{aligned} & \text { effect of the interaction of the } i \text { th curve } \\ & \text { type with the jth curve group with the kth }\end{aligned}$ curve position with the ith vehicle type with the nth station on the lateral placement of a vehicle,

$n L(i j k]) m n=$ effect of the interaction of the error due to the nesting of the m replicates within the $i$ th curve type, jth curve group, kth curve position and 1 th vehicle type with the nth station on the lateral placement of a vehicle,

$\varepsilon(i j k 1 \mathrm{mn})=$ error within the ith curve type, $j$ th curve group, kth curve position, ith vehicle type, mth replication and nth station,

i $\quad=7,2$,

j $\quad=1,2,3,4$,

k $\quad=1,2,3,4$,

$1=1,2,3$,

m $\quad=1, \ldots, 10$, and

n $\quad=1, \ldots, 11$.

The split-plot type analysis was used because this model mathematically resembles the data collection method. The word "plot" has been inherited from agricultural applications. When a plot of ground was selected for an 
experiment, this plot was often divided, or "split," into many smaller plots for data gathering and analysis purposes. The required data for the "whole plot" were gathered by choosing the "split-plots" randomly within the whole plot. This procedure restricts the randomization of the split plots to the population defined by the whole plot.

These restrictions on randomization, while vital to the theory of the split-plot type analysis, do not normally appear in the split-plot type model. V. L. Anderson has proposed the use of restriction errors for these models to account for this deficiency. Restriction errors that correspond with every restriction on randomization in the experimental design were introduced into the model. These restriction errors, although they have no degrees of freedom and no sum of squares, force the experimentor to recognize the limitations of his statistical design (1). Error terms of this type were used in the model described in this investigation.

Referring to the logic diagram in Figure 1 and the previous explanation of the data collection process, the following reasoning was used in developing the model. The variables of curve type (S) and curve group (V), along with their interaction (SV), were considered the whole plot of the experimental design. These factors were selected first, and all other factors were chosen after these two factors were decided. Because these factors were limited to narrow ranges, 
a restriction on randomization occurs and is accounted for in the model by the error term $\delta$.

In the next step, the four curve positions (P) were fixed within each of the eight combinations of curve type and curve group. These four positions A, B, C, and D, were randomly chosen within each curve group and type and formed the first split-plot of the desigr. Because the four positions were chosen randomly within the limits of a specific curve group and type, a restriction on randomization occurred, and was accounted for in the model by the error term $\omega$.

For each curve position (the first split-plot) within each curve type and group (the whole plot), measurements were taken randomly for each of the three vehicle types ( $T$ ) to form the second split of the design. Ten measurements were obtained for each vehicle type at each curve position. Because these observations of vehicle type $(R)$ were taken randomly from a very large population of possible values, the samples were considered to be nested within the vehicle type. A nesting error, $n$, was used as the restriction error for this level of the model formulation.

Finally, the stations (L) were considered to be fixed within each of the previous levels of vehicle type (T) and provided the third split level of the model. The measurements 
were taken at each station for each vehicle type, and the stations were chosen after the vehicle type was selected. An interaction of station $(L)$ and the nesting error $(n)$ occurs as part of the split-plot type analysis, and this interaction $(n L)$ was used for the final error at this level of the model.

Using this mathematical model, the data were analyzed to determine the statistical significance of the various terms and their interactions in the model. The effects of the factors considered in the study on the paths of vehicles negotiating horizontal curves were then analyzed using standard statistical tests and are discussed in the results. 


\section{RESULTS}

After the data were collected and the mathematical analysis was performed, the results of the analysis were interpreted to evaluate the influence of transition curves on driver behavior. The results of the various statistical tests are summarized, and the meanings of these tests are explained in relation to the factors considered in the study.

The results of the analysis are summarized in Table 2, which includes the degrees of freedom, sum of squares, mean square and expected mean square for each term in the statistical model. The terms in the expected mean squares were used to indicate the statistical tests that were necessary to evaluate the results of the experiment. In accordance with standard statistical methods, the significance of the terms S, V, and SV should be tested with the use of the error term, $\delta$, and the second error term, $\omega$, should be used to test the statistical significance of the terms $P, S P$, VP and SVP. The error term in each of the other split-plot levels was used to test the significance of the terms of that level.

\section{Determination of the Error Terms}

Although the tests of significance for the terms in the model appear to be straightforward, a closer examination 


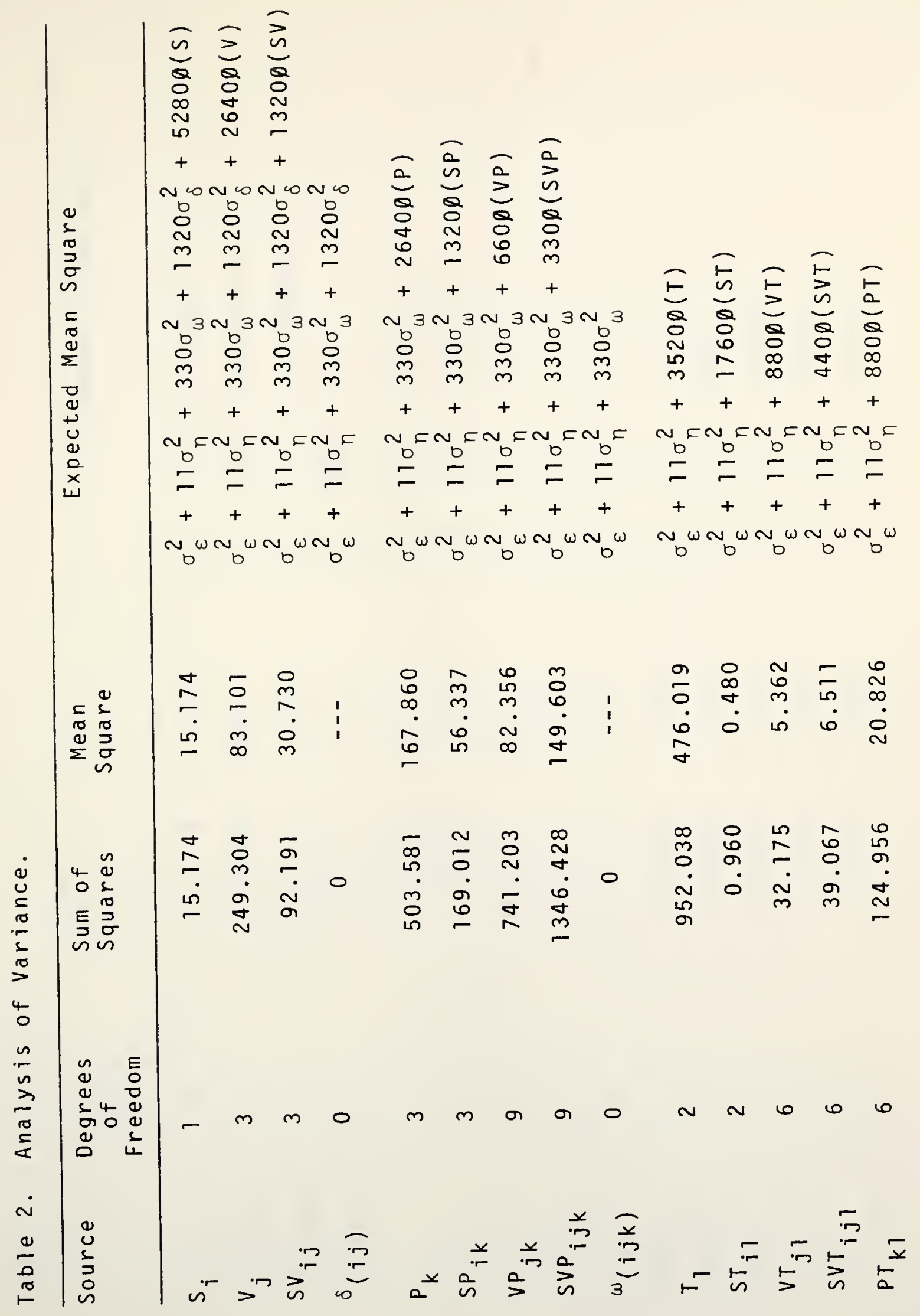




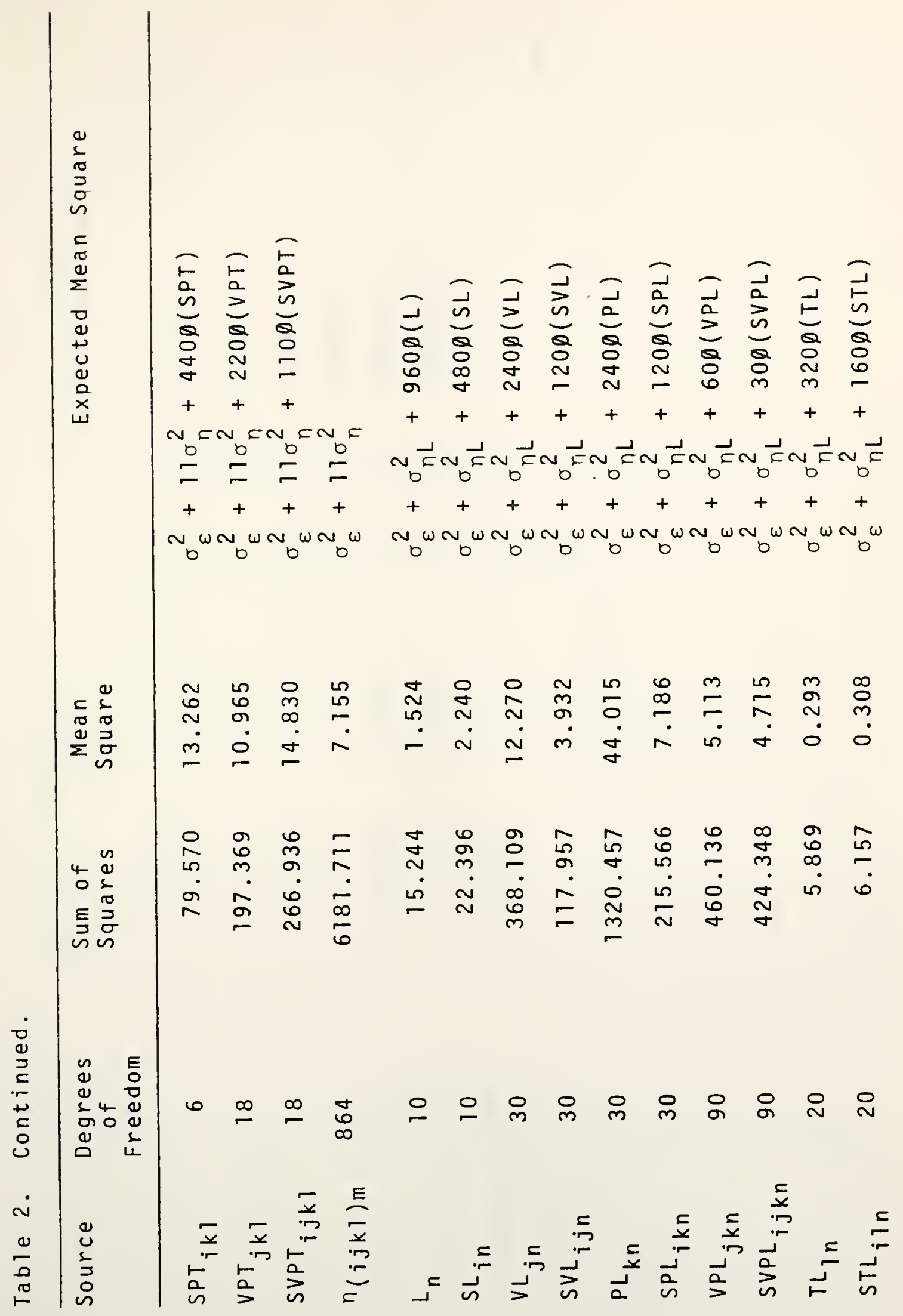




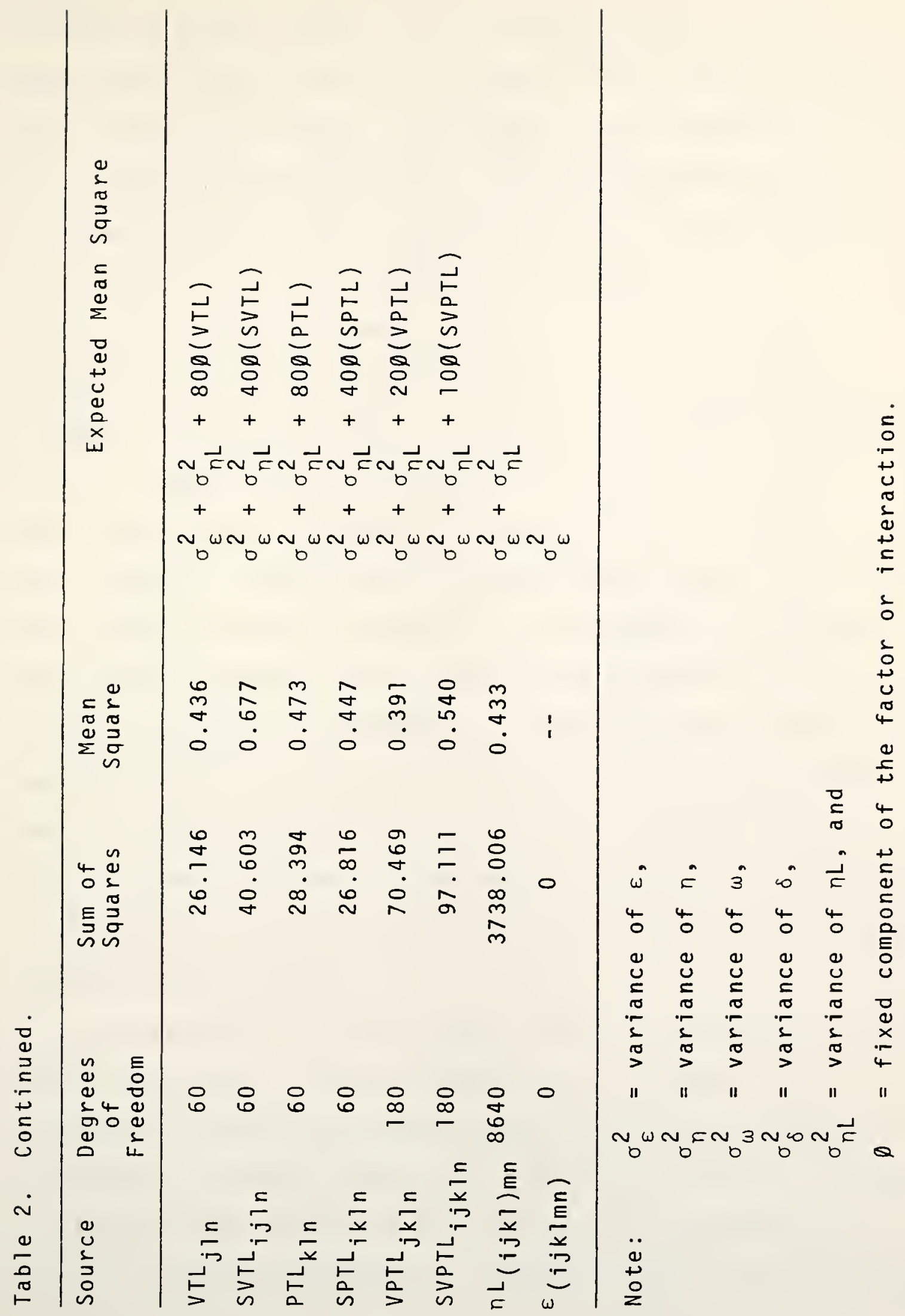


of Table 2 reveals that the tests which utilize the two error terms $\delta$ and $\omega$ can not be made. These two errors have zero degrees of freedom, and although these two errors could be estimated if replicate curve data were available, such data were not available for this study. In this split-plot experiment with no replication, the interaction of the whole-plot factors and the interaction of each split-plot factor with all other factors within which it is set were assumed to be non-existent. Any such interaction disclosed in the analysis may over-estimate the true error causing fewer significant differences than may really be there. In this case, the interactions SV and SVP were used as the correct errors and $\emptyset(S V)$ and $\emptyset(S V P)$, the components of SV and SVP in the estimated mean squares, were assumed to be zero. However, in this study these two interactions have practical meanings and the assumption that they are zero places some doubts on the results. It should be pointed out, however, that this merely makes all the tests conservative since the error may be larger than the true error. This in turn makes the observed $F$ smaller.

An estimate of the whole plot error is developed in the following manner. As the degree of curve changes, the placement of vehicles on unspiraled curves may be expected to change, as shown by the line marked "no spiral" in figure 3. Because the purpose of the spiral is to simulate the driver's path upon entering or leaving a curve, no differences 


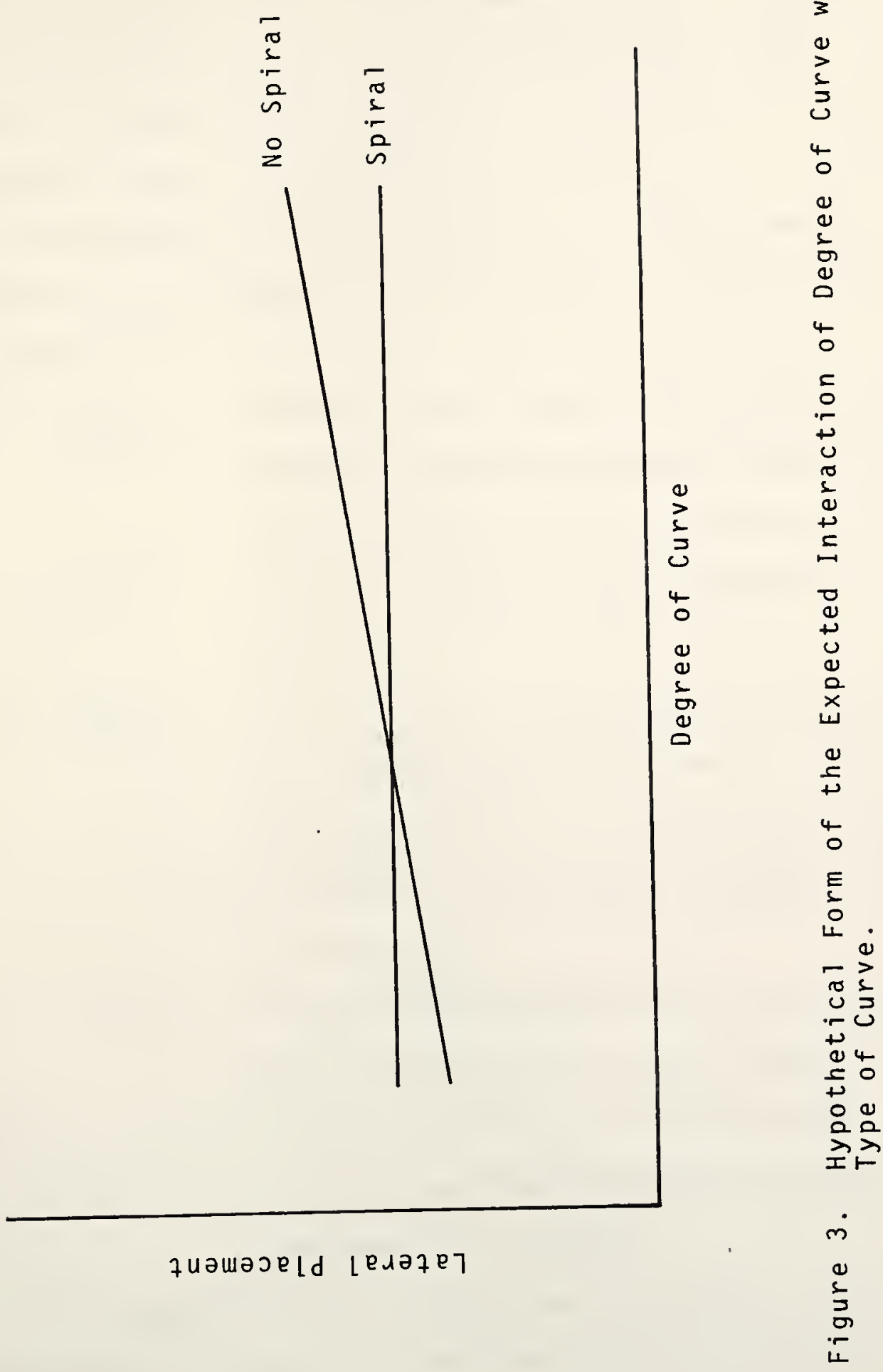


in lateral placement among different degrees of curve are expected on spiraled curves. This effect is shown graphically by the horizontal line marked "spiral" in Figure 3.

Curve Groups 1, 2 and 3 are different from Group 4 with respect to pavement width, and these three groups are equally spaced with respect to degree of curve. The sum of squares of the interaction of curve type (SV) with three degrees of freedom is partitioned into the following three orthogonal contrasts:

1. $S V_{L 123}=$ effect of the interaction of curve type with the linear component of the first three groups of the curve group classification on the lateral placement of a vehicle,

2. $S V_{Q 123}=$ effect of the interaction of curve type with the quadratic component of the first three groups of the curve group classification on the lateral placement of a vehicle, and

3. $S V_{4 \times 123}$ = effect of the interaction of curve type with the fourth curve group taken in contrast to the other three groups of the curve group classification on the lateral placement of a vehicle.

The expected interaction of curve type with curve group is the contrast $\mathrm{SV}_{\mathrm{L} 123^{\circ}}$. As predicted, this contrast accounts 
for a large portion of the sum of squares of the interaction. The other two contrasts, $S_{Q 123}$ and $S_{4 \times 123}$, are considered to be error terms and are combined and used as an estimate of the error. With this estimate of the first error, the main effects of curve type and curve group and the extracted interaction that estimates the total interaction of curve type with curve group were tested. The results of these statistical tests are presented in Table 3 .

An estimate of the second error ( $\omega$ ) was obtained in a similar manner. The following three of nine possible orthogonal contrasts were partitioned from the interaction SVP:

$$
\begin{aligned}
& \text { 1. } S V_{L 123^{P} A C} \\
& \text { 2. } S V_{L 123^{P}}{ }_{B D} \text {, and } \\
& \text { 3. } S V_{L 123^{P} A C B D}
\end{aligned}
$$

where

$$
\begin{aligned}
& S \text { = effect of the type of curve on the lateral } \\
& V_{L 123}=\text { effect of the linear component of the first } \\
& { }_{A C}=\text { effect of the differences } \\
& \text { of the positions } A \text { and } C \text { of the position on }
\end{aligned}
$$




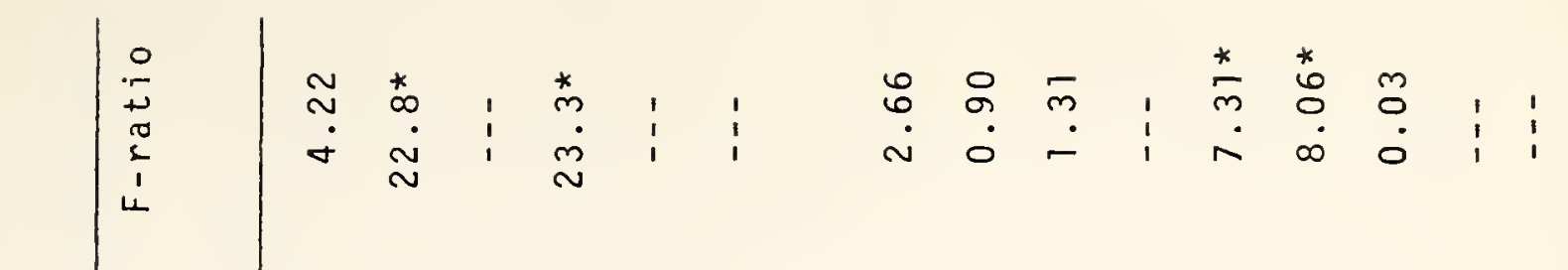

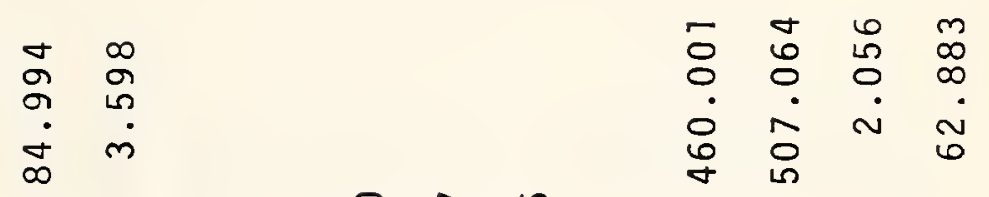

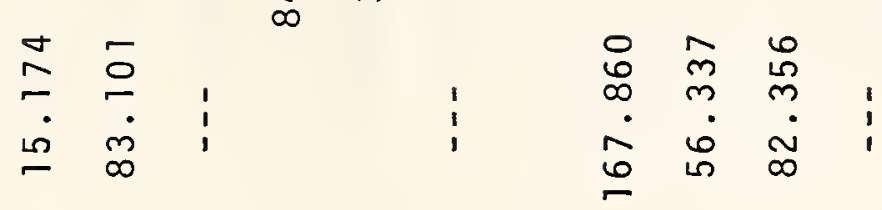

$$
\begin{aligned}
& \left.\underset{\substack{0 \\
0}}{0}\right|^{\Sigma}
\end{aligned}
$$

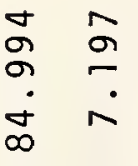

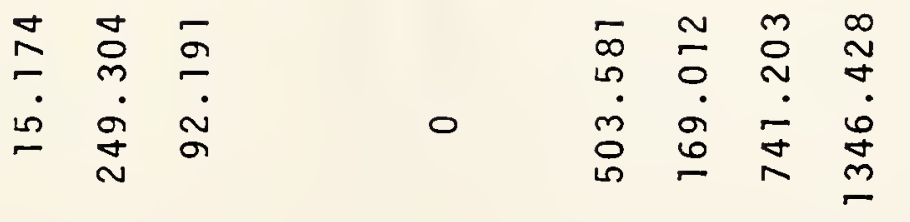

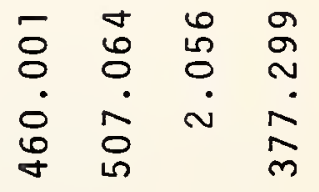

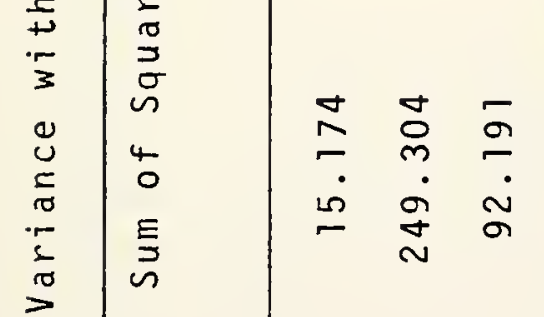

$$
\begin{aligned}
& 4 \\
& \begin{array}{lll}
\sim & & \\
\sim & n & E \\
& 0 & 0 \\
0 & 0 & 0
\end{array} \\
& \text { बे } \\
& -N \\
& \text { o m a } a \\
& \text { - }-6
\end{aligned}
$$

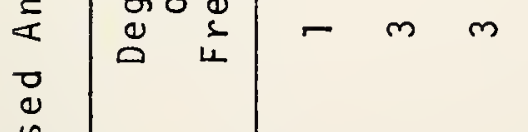

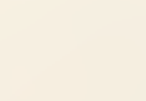

$$
\begin{aligned}
& \begin{array}{l}
\sim \\
\stackrel{\sim}{a} \\
\sim
\end{array}
\end{aligned}
$$

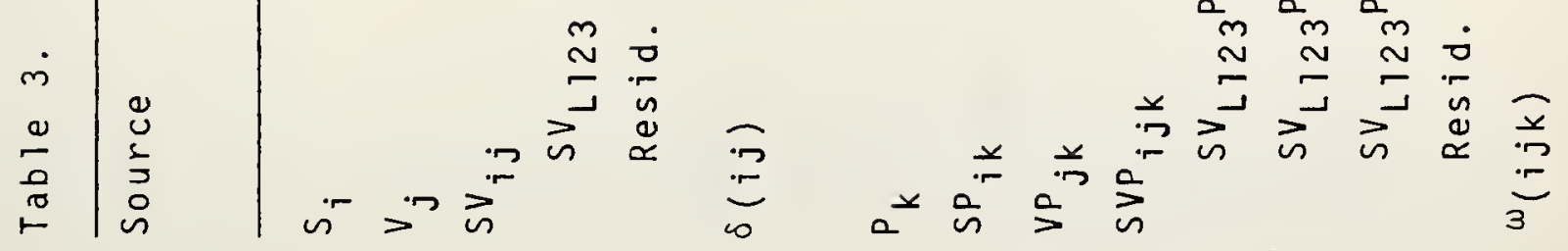

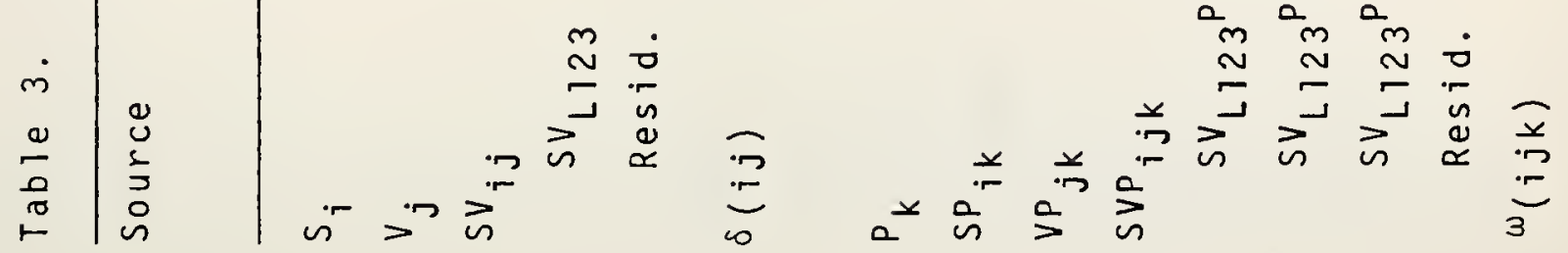




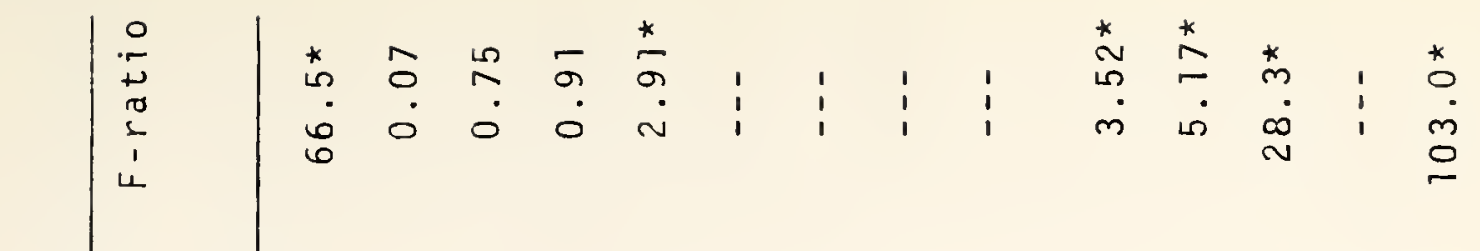

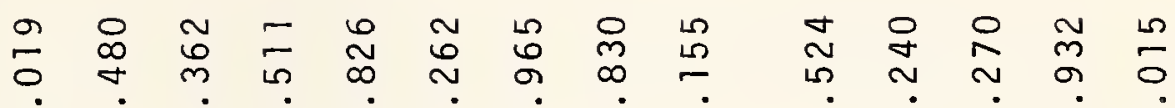

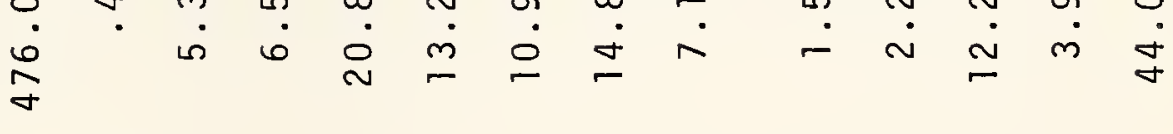

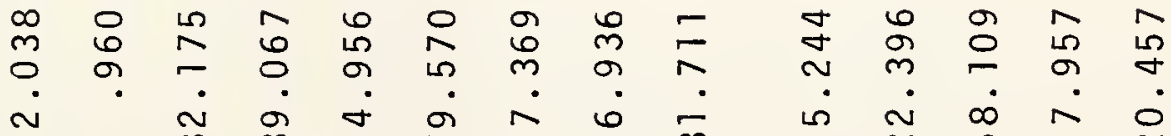

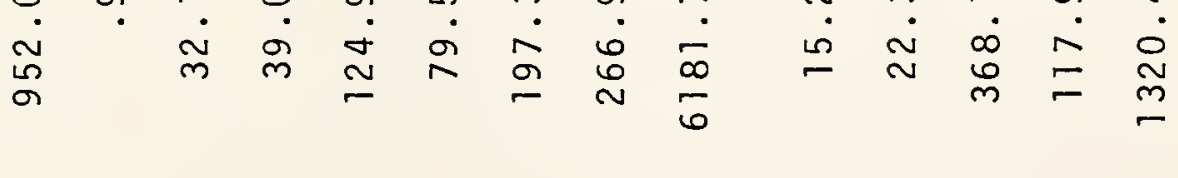

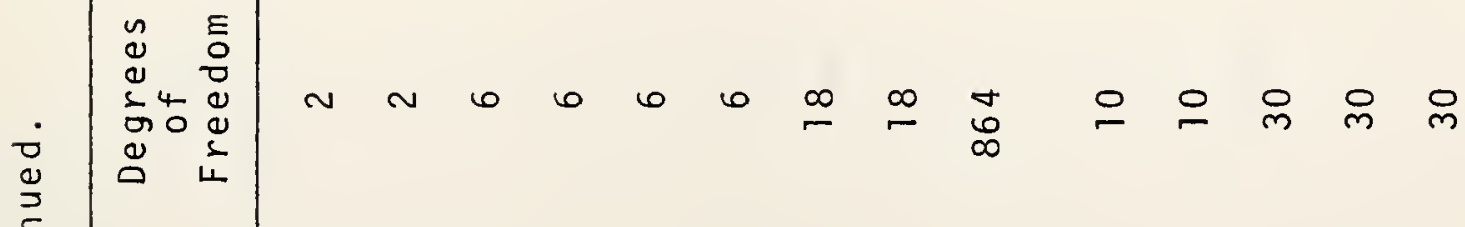

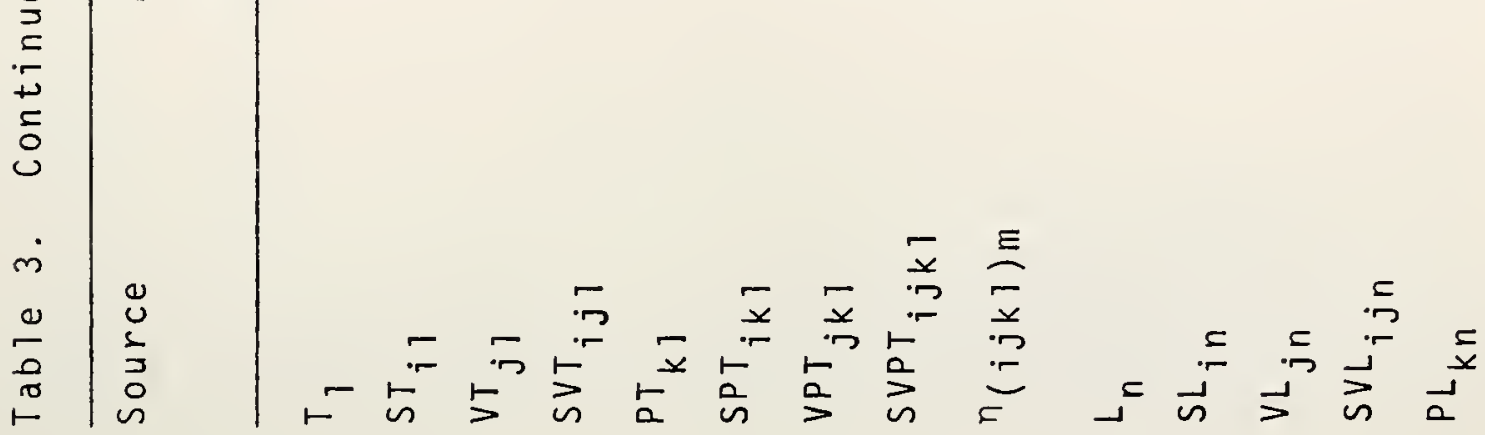




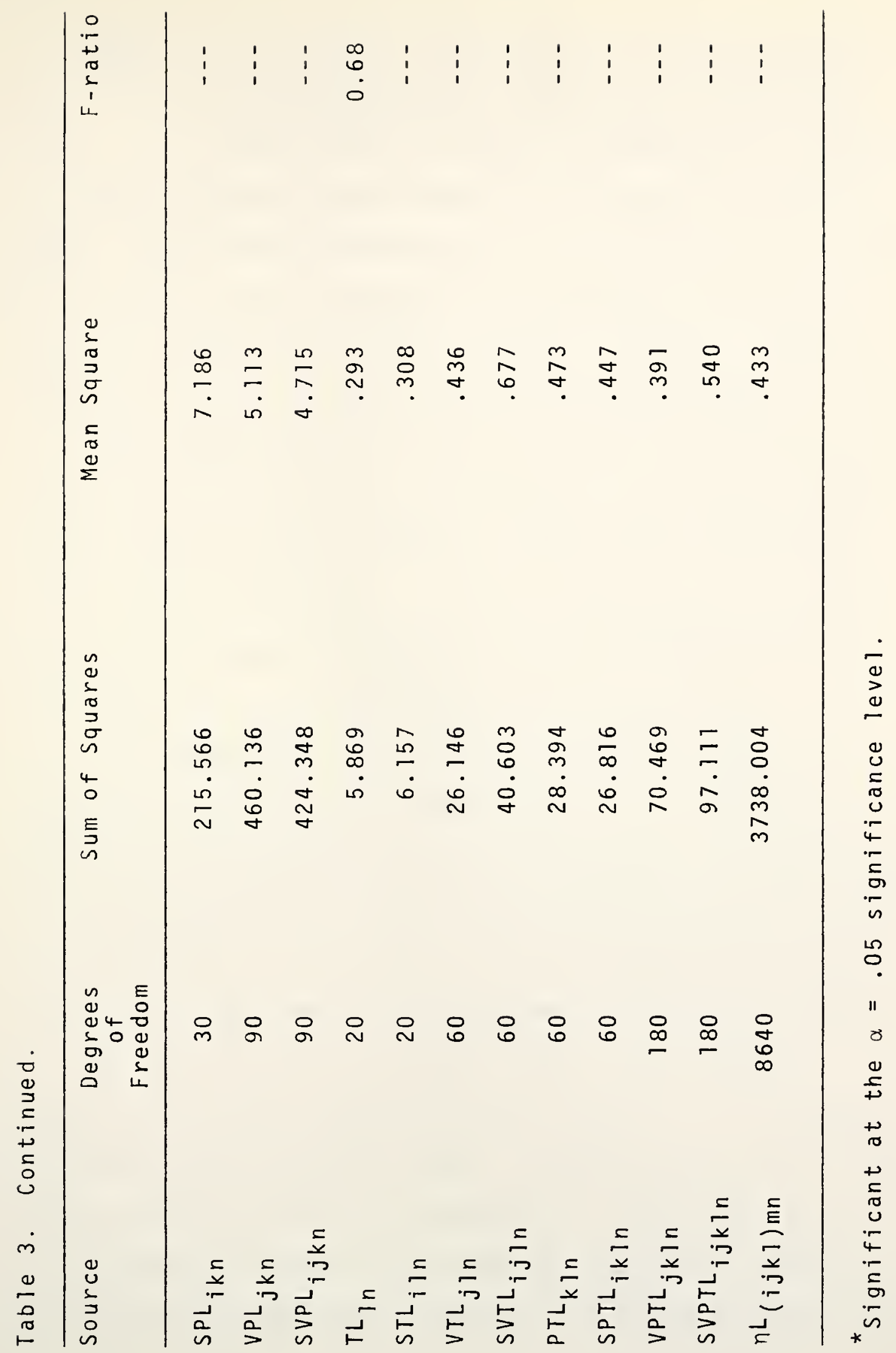




\section{$P_{A C B D}=$ effect of the differences of the combination of positions $A$ with $C$ and $B$ with $D$ of the curve position classification (reflects the differences between incoming and outgoing traffic) on the lateral placement of a vehicle.}

These contrasts were deemed to be important because, in light of the previous discussion on the interaction of curve type with the linear component of curve group $\left(S_{L 123}\right)$, they were considered to have practical meanings. The contrast of SV $L 123_{A C}$ is the effect of the differences in traffic coming into each end of the curve on the expected interaction of curve type with curve group, and $S V_{L 123} P_{B D}$ represents the differences in traffic leaving each end of the curve on that interaction. Finally, SV $1233_{A C B D}$ is the effect associated with the differences in vehicles entering and leaving the curve on the expected interaction.

The remainder of the interaction SVP was used as an estimate of the first split-plot error $(\omega)$. This error estimate was then used to test the effect of curve position $(P)$, the interaction of curve group with curve position (VP), and each of the three contrasts partitioned from the interaction SVP. The results of these tests are given in Table 3 . Nesting of vehicles within vehicle type permits an estimate of the second split-plot error, $n$. This term was used to test the main factor and the interactions in the second split-plot level of the model. The interaction of this second split-plot error with the station of measurement $(n L)$ tests the significance of the terms in the third 
split-plot level. The error within the cells, $\varepsilon$, cannot be estimated because of the lack of replicate horizontal curve data. However, this term serves no purpose in the model except for a significance test of $n \mathrm{~L}$. This test is not necessary because there is no need to know if the variance of $n L\left(\sigma_{n L}^{2}\right)$ is zero to use the estimated mean squares containing this term.

\section{Analysis of the Results}

As summarized in Table 3 , the following main effects and interactions were found to be statistically significant at the 5-percent level:

1. $V$ effect of curve group on the lateral placement of a vehicle,

2. SVL123 = effect of the interaction of curve type with the linear component of the first three curve groups on the lateral placement of a vehicle,

3. $S V_{L 123} P_{A C}=$ effect of the interaction of curve type with the linear component of the first three curve groups with curve positions $A$ and $C$ on the lateral placement of a vehicle, 
4. $S V_{L 123} P_{B D}=$ effect of the interaction of curve type with the linear component of the first three curve groups with curve positions $B$ and $D$ on the lateral placement of a vehicle,

5. T = effect of vehicle type on the lateral placement of a vehicle,

6. PT = effect of the interaction of curve position with vehicle type on the lateral placement of a vehicle, 7. $L$ effect of the station of measurement on the lateral placement of a vehicle,

8. $S L$ effect of the interaction of curve type with station of measurement on the lateral placement of a vehicle, 9. $V L=$ effect of the interaction of curve group with station of measurement on the lateral placement of a vehicle, and

10. PL = effect of the interaction of curve position with station of measurement on the lateral placement of a vehicle. All third and higher order interactions, except the three contrasts partitioned from the interaction SVP, were not tested because these conditions have no practical significance even if they are statistically significant. The 
factors and interactions which proved to be significant in the model were more carefully scrutinized to explain, if possible, the causes of their significance.

The average lateral placement of vehicles from the roadway centerline for each curve group is shown in figure 4. The characteristics of the curve groups are given in Table 1. The effect of this faccor was investigated by first extracting the sum of squares that are due to the fourth curve group $V_{4}$. The pavement widths of Group 4 are $22 \mathrm{ft}$, whereas the other pavements are $24 \mathrm{ft}$ wide. As illustrated in Table 4, this term is statistically significant, and the hypothesis that measurements taken on 22-ft pavements are similar to those taken on $24-\mathrm{ft}$ pavements is rejected.

Because Groups 1 and 4 have the same degree of curvature but different pavement widths, a contrast of these two groups was made. This contrast $\left(V_{1 \times 4}\right)$ is significant, and differences exist on the two widths of pavement for the same degree of curve. A third contrast, $V_{123}$, evidences no significant differences among the three groups with the same pavement width; that is, these data show no significant differences in lateral placement for the range of curvature evaluated.

The contrast SV $\mathrm{L}_{123}$ represents the expected effect of the interaction of curve type with curve group. This effect is significant and accounts for 90 per cent of the sum of squares of this interaction. Therefore, the assumption 


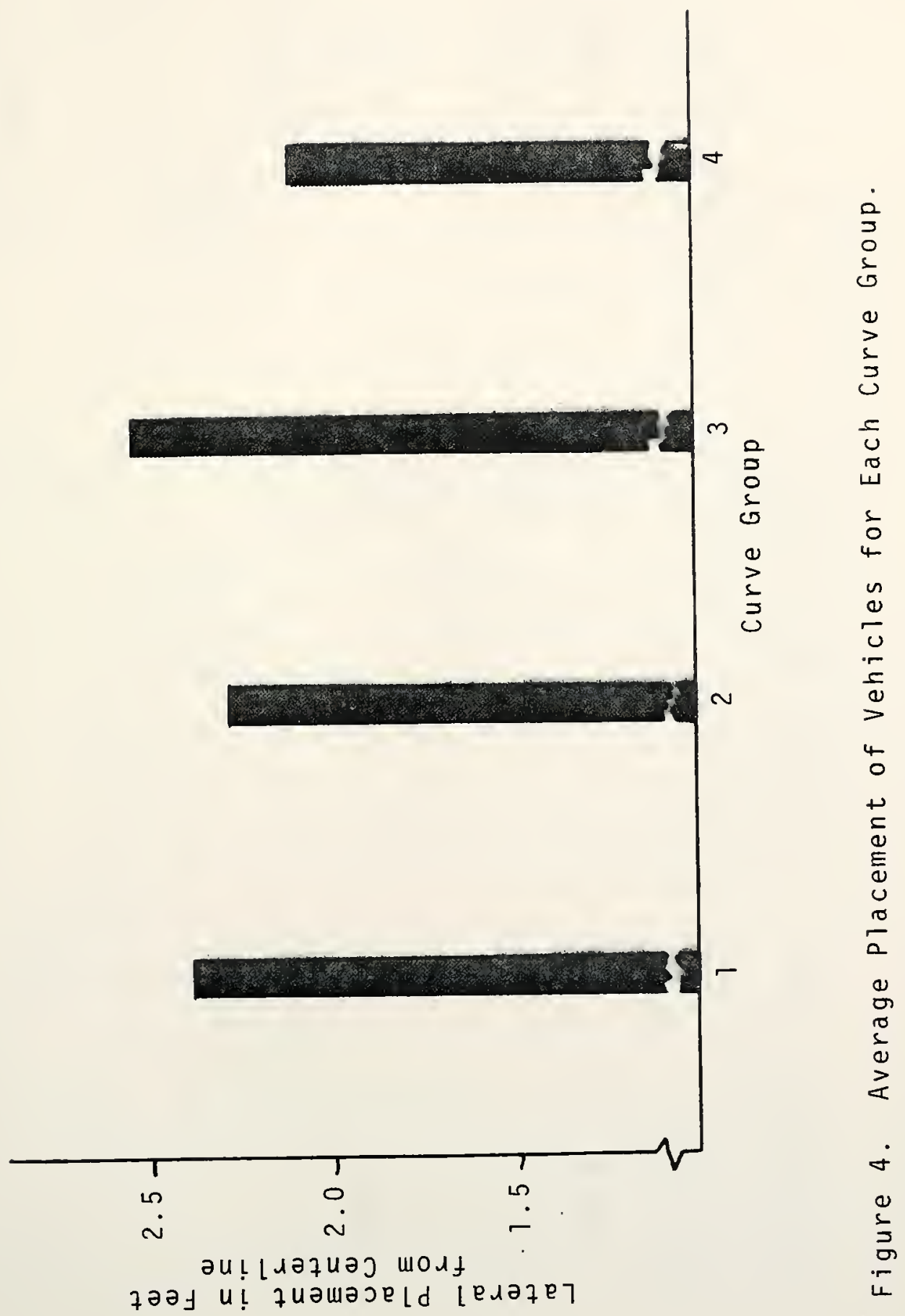




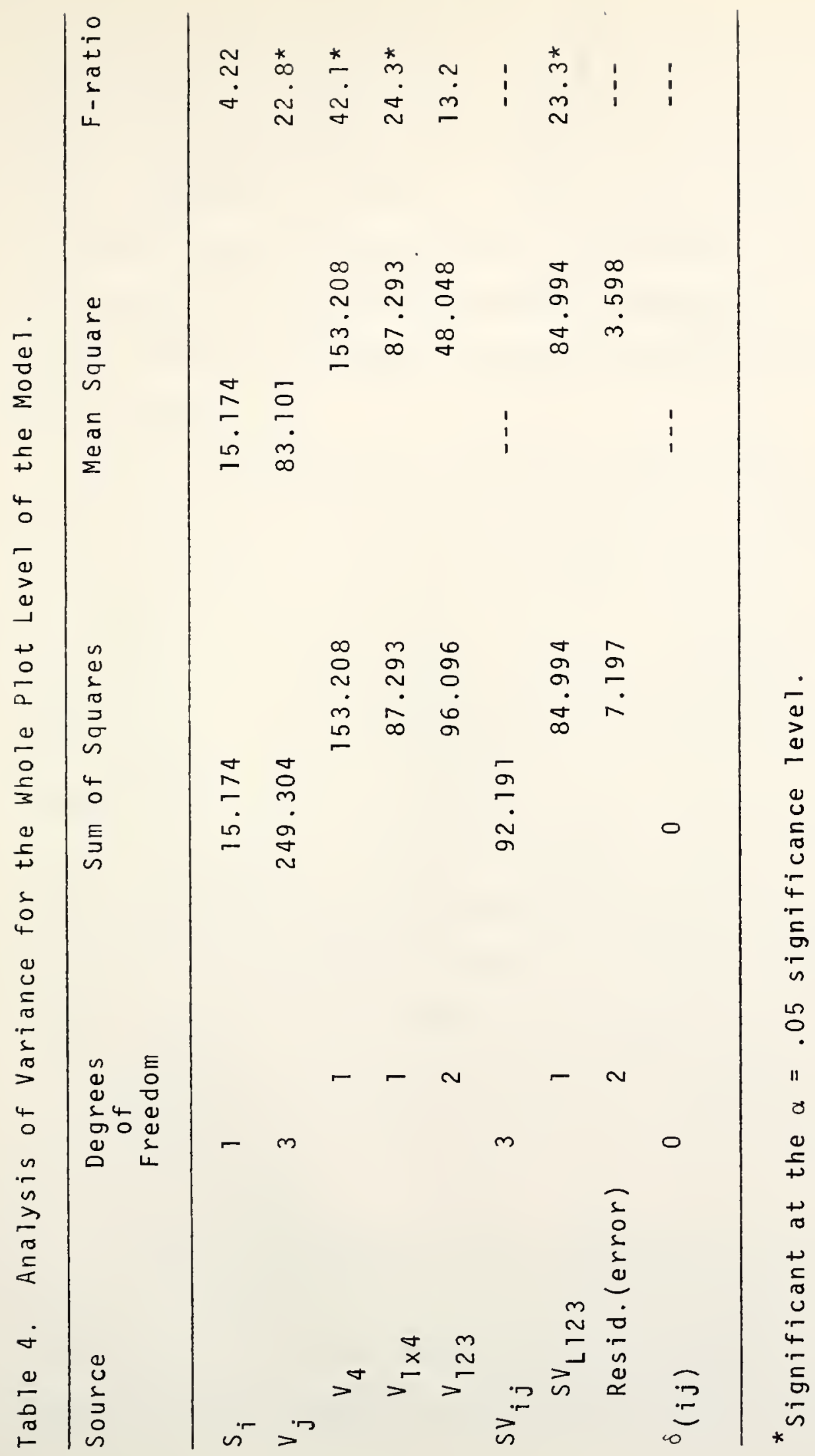


that this contrast represents the interaction SV appears to be acceptable for these data. The interaction of curve type with the first three groups of the curve group classification is depicted in Figure 5. The lateral placements on the spiral curves are nearly on a horizontal line, whereas the plot for the unspiraled curves is broken and evidences greater lateral placement from the centerline with increasing curvature.

Because the term $S V_{L 123^{P}}{ }_{A C}$ was significant in the statistical test, the expected interaction of curve type with curve group is not zero when taken with the effects of the entering curve positions $A$ and $C$. No apparent relationship exists in Figure 6 among the three components of the term $S V_{123} P_{A C}$, and this finding indicates the presence of interaction. A similar effect is seen for the representation of $S V_{123} P_{B D}$ in Figure 7 . Vehicles entering or leaving spiraled curves react differently to the various degrees of curve than those vehicles entering or leaving unspiraled curves. However, the contrast $S V_{L 123^{P}}{ }_{A C B D}$ is not significant; on the average, there are no differences between the entering and leaving positions of curves for the degrees of the two types of curves.

Because SV 123 PACBD was not statistically significant, the sum of squares associated with this contrast was pooled with the error term to provide another degree of freedom. Forming the error term in this manner changed the associated 


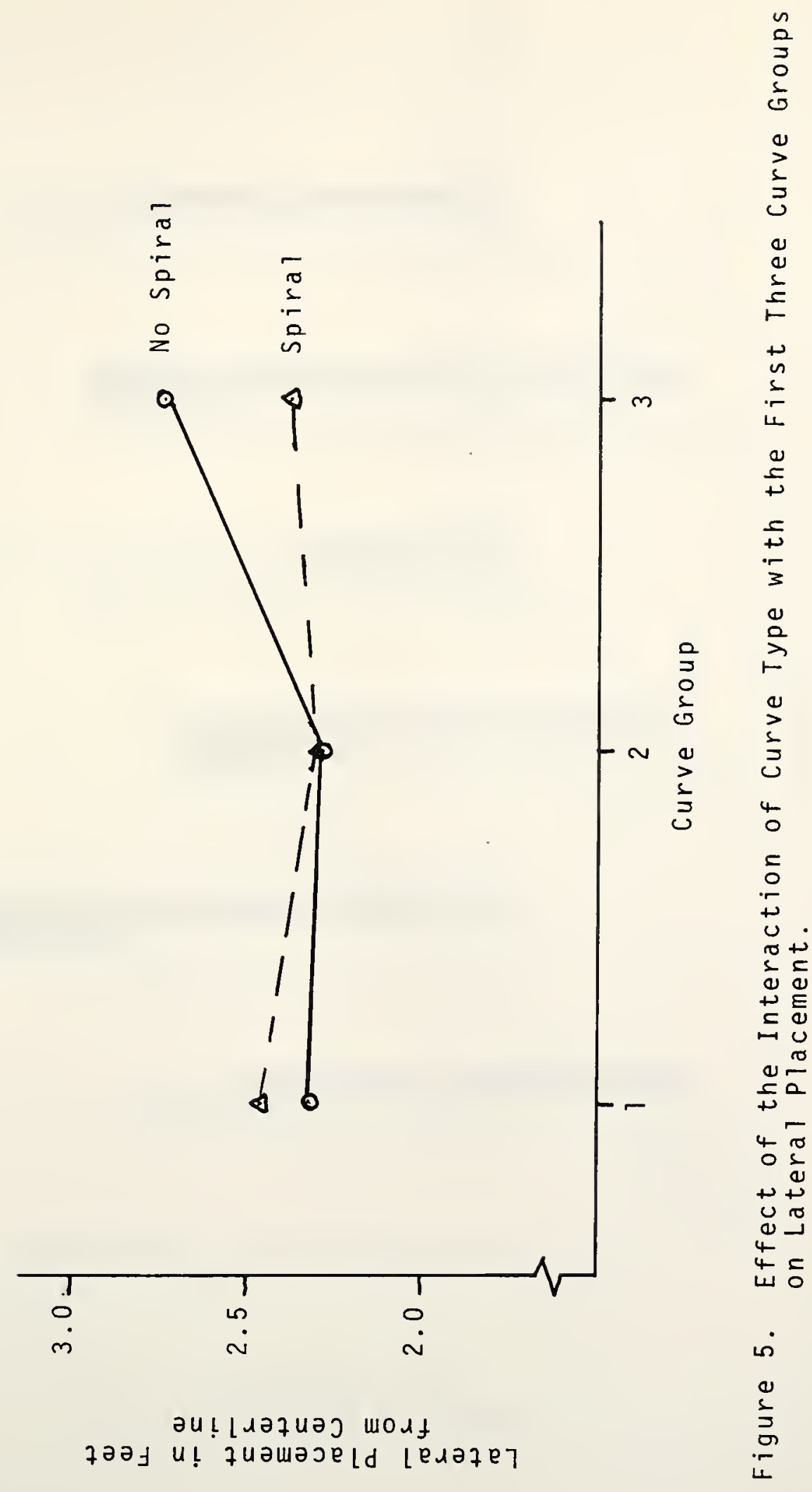




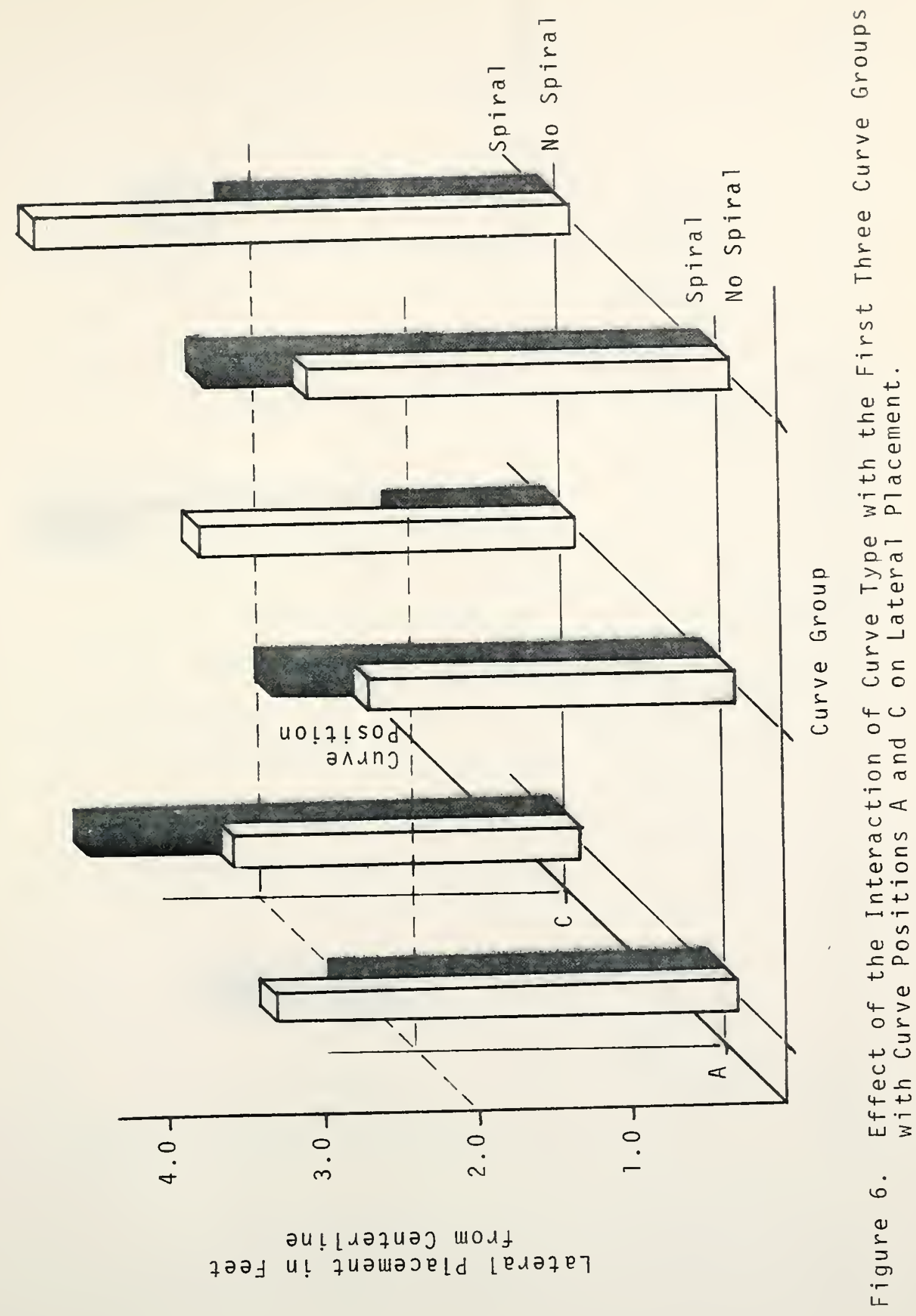




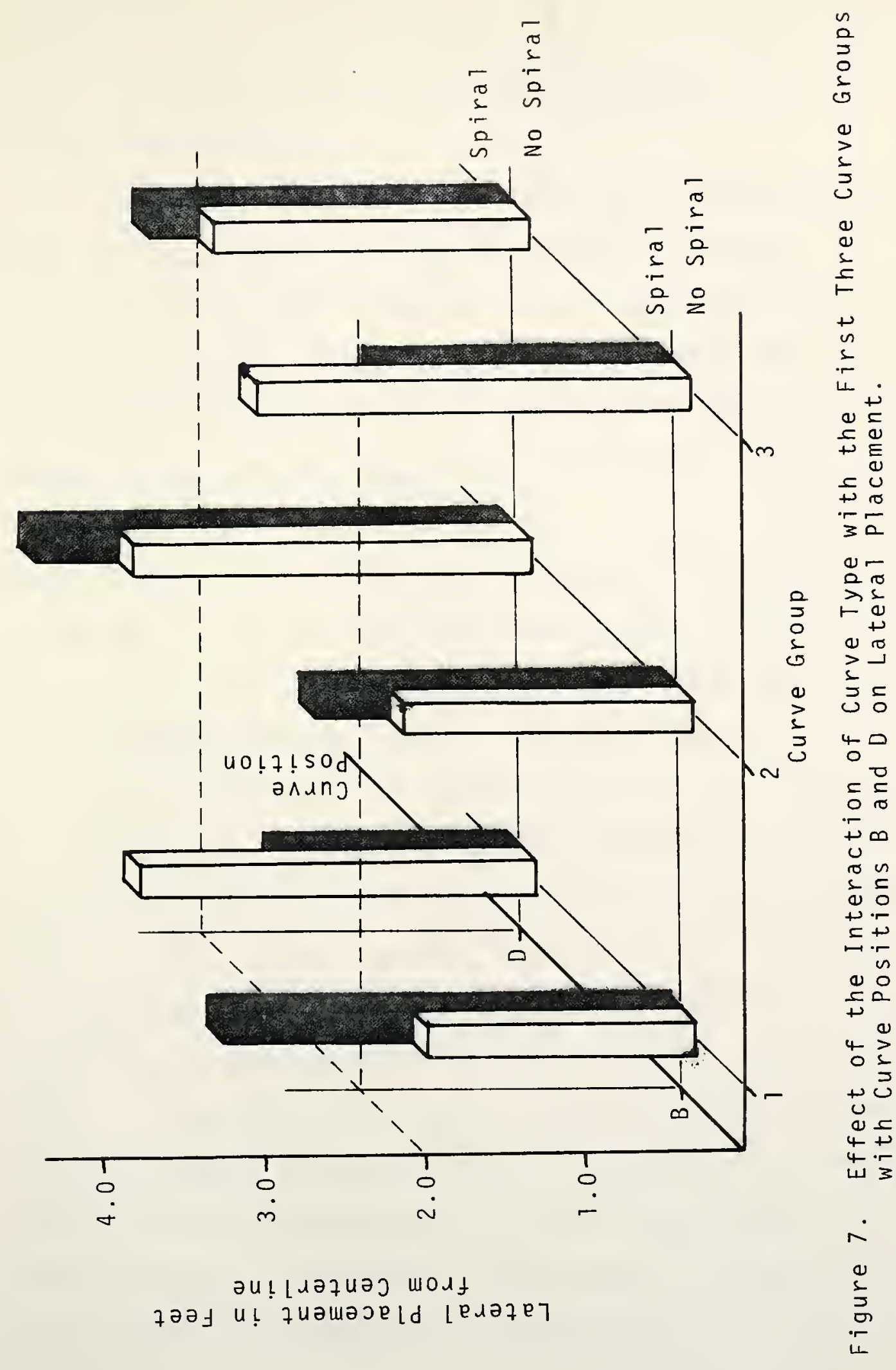


$F$ values but did not greatly change the significance of any variables in the first split-plot level. The revised results of the statistical tests for the pooled data are summarized in Table 5 .

Variable $T$, vehicle type, was investigated by extracting from the total sum of squares the effect associated with the differences between the two truck types, the single-unit truck and the truck combination, because these two types of vehicles were assumed to have similar placement characteristics. The contrast, $T_{23}$, is illustrated in Table 6 and was found to be significant even at the $\alpha=.01$ significance level. Tests of the contrasts of passenger cars with singleunit trucks and cars with truck combinations produced similar results. The conclusion is that the three vehicle types have different average lateral placements while translating horizontal curves both with and without spirals.

The effects of the interaction of position on curve with type of vehicle are shown in Figure 8 , and the contrasts given in Table 6 were used to investigate this interaction. The four curve positions are as shown in Figure 2. The only significant contrasts include Vehicle Type 3 , truck combinations. At position $C$ the truck combinations are further from the roadway centerline than is expected when compared with the relative measurments of the vehicle types at the other positions. Apparently, the drivers of combination trucks know the non-tracking characteristics of their vehicles 


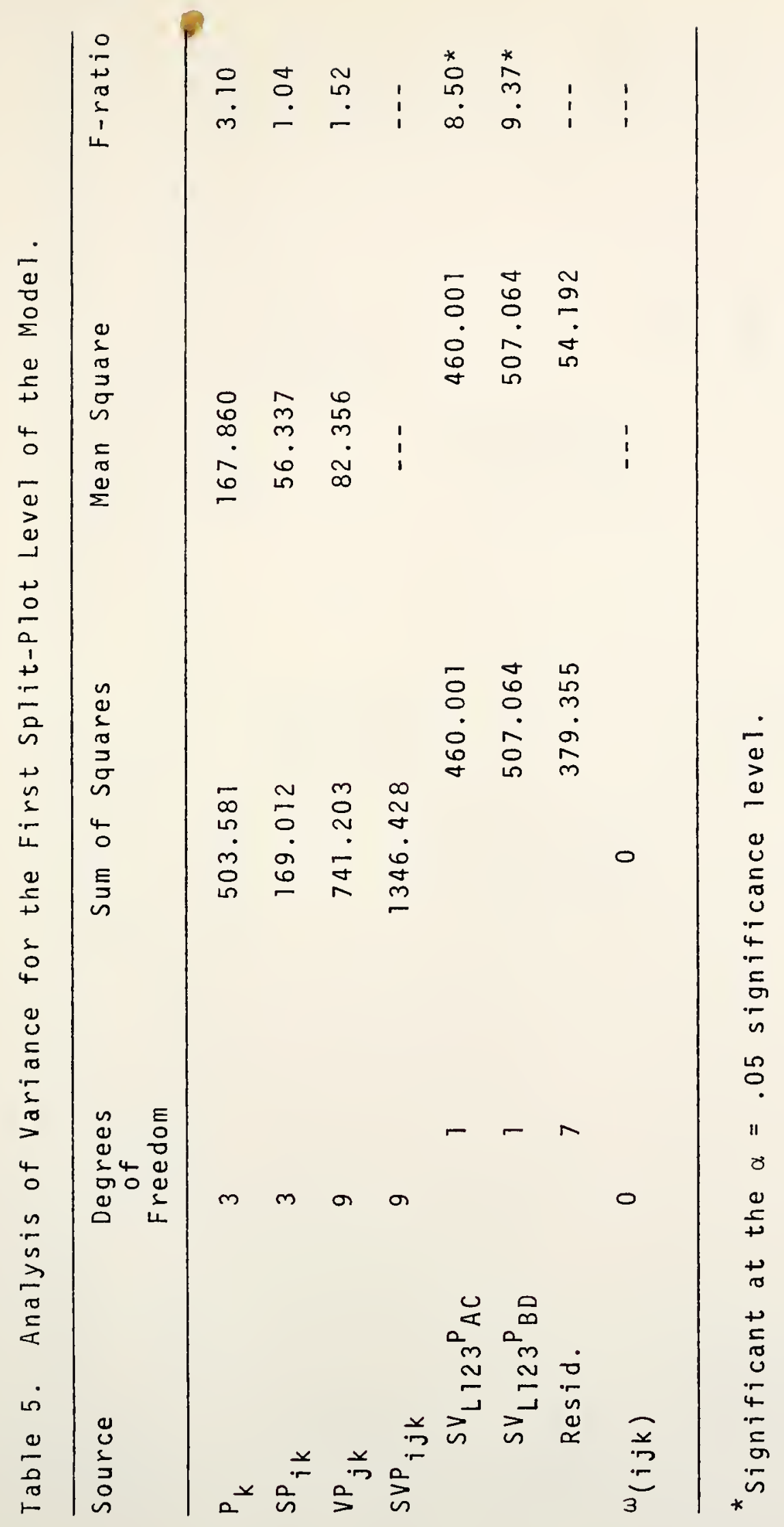




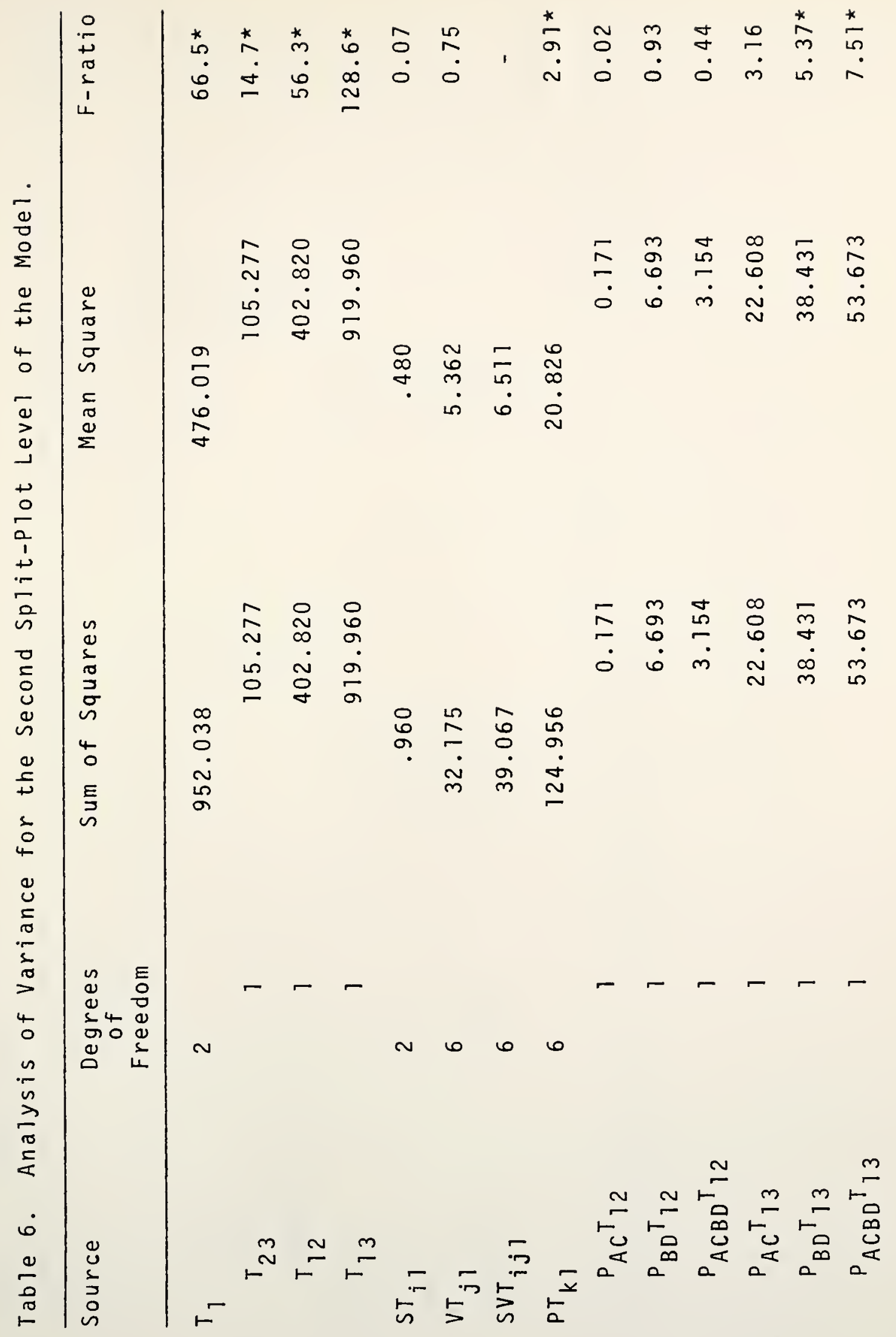




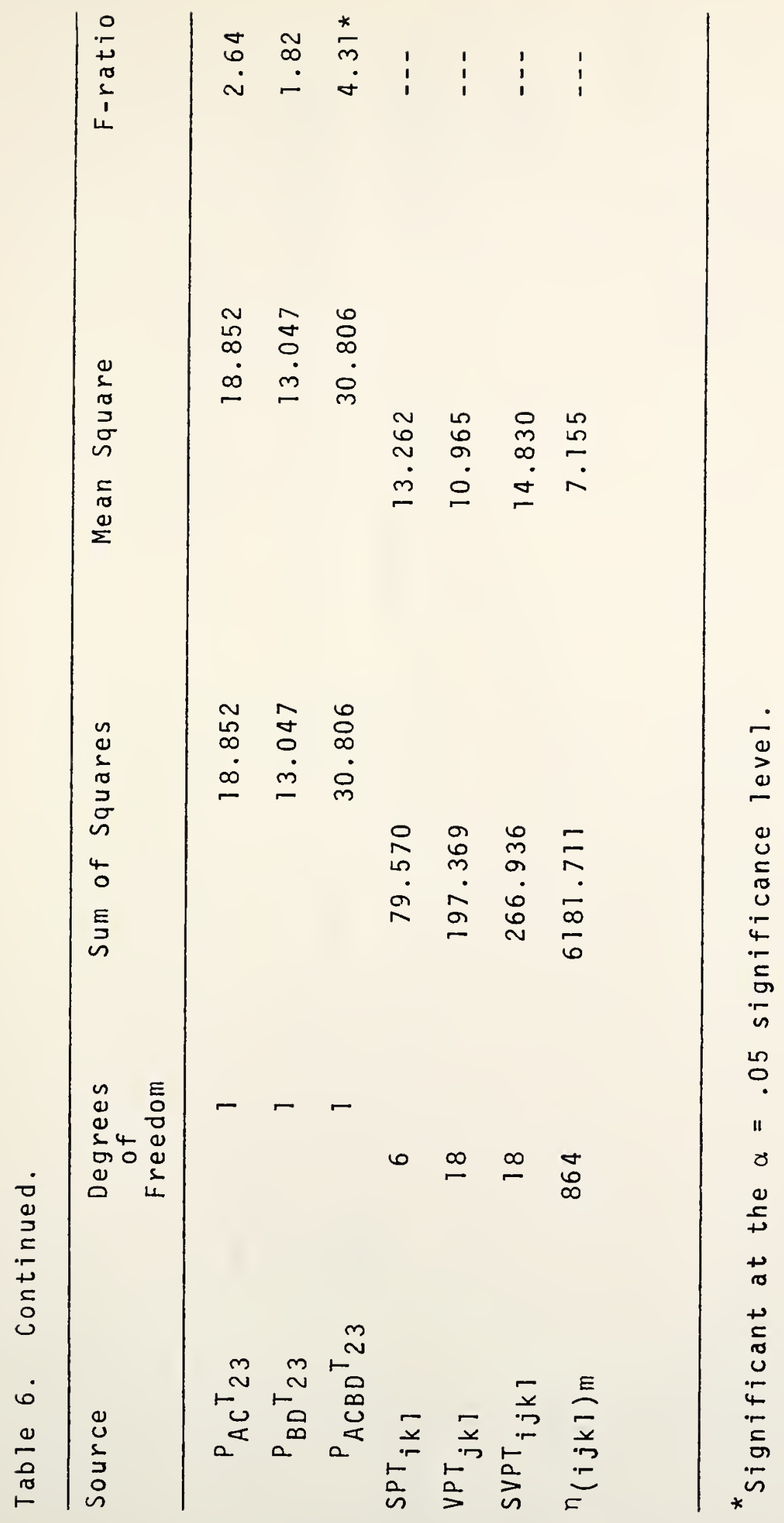




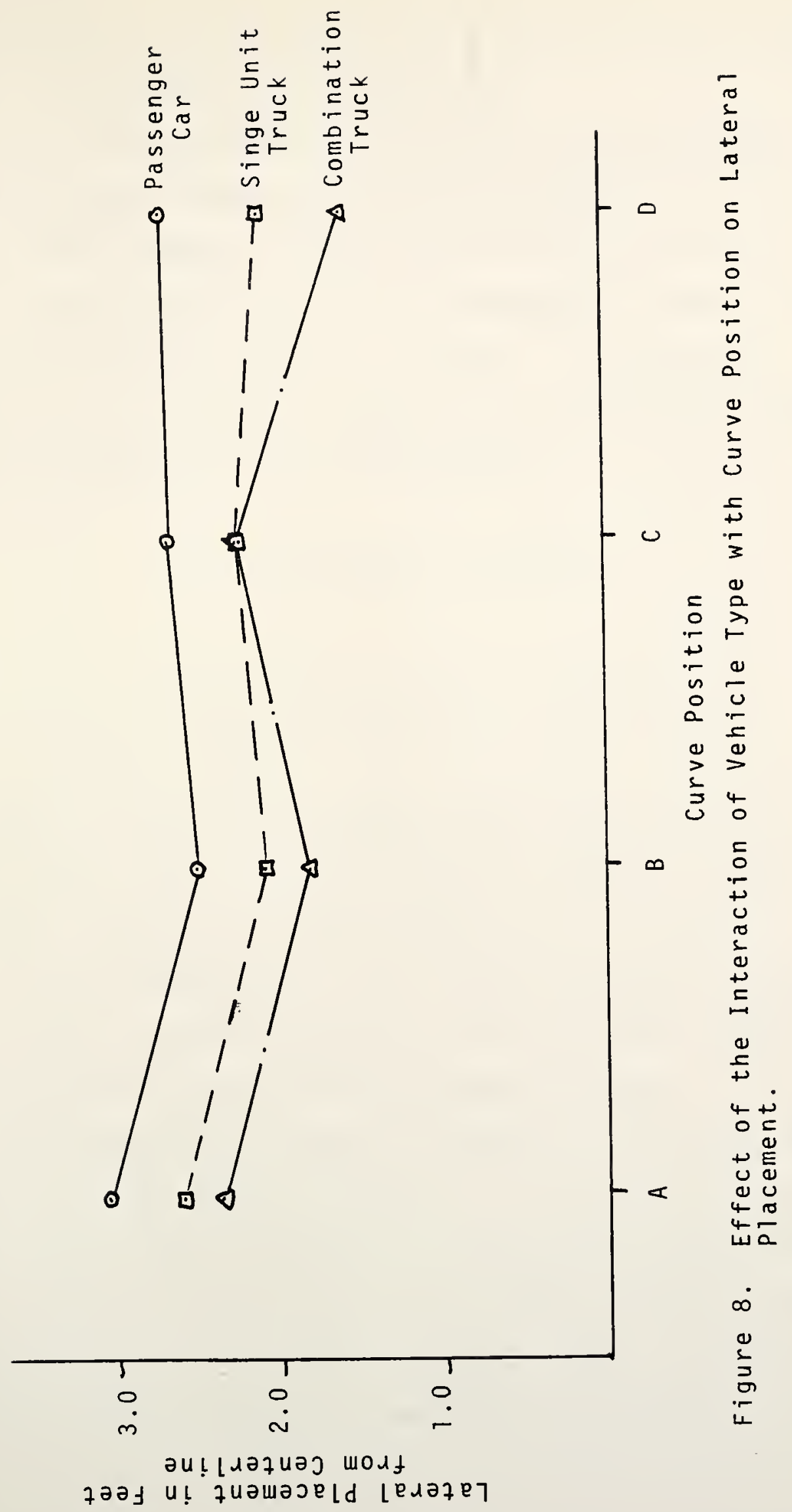


and steer away from the centerline so that the rear wheels do not infringe upon the inside lane.

The linear component of the station of measurement was significant with respect to lateral placement, while the higher order components contributed very little to this effect. These test statistics are presented in Table 7 for the third split-plot level of the model. A regression analysis of the average placement of the vehicles at each station produced the following equation:

$$
Y=2.275+0.01045 L
$$

where:

$$
\begin{aligned}
& Y=\text { average lateral placement of a vehicle, and } \\
& L=\text { station number. }
\end{aligned}
$$

As a vehicle progresses through a curve end, the driver tends to move away from the centerline toward the edge of the road. This path is shown graphically in Figure 9. However, this information has little meaning because the paths of vehicles are much different for the two curve types, the four curve groups, and the four curve positions.

The interaction of type of curve with station of measurement $(S L)$ is shown in Figure 10. The points on this graph of the lateral placement of vehicles on those curves with no spiral are more nearly horizontal than the corresponding points of vehicles on spiraled curves. Vehicles on spiraled curves tend to move away from the roadway 


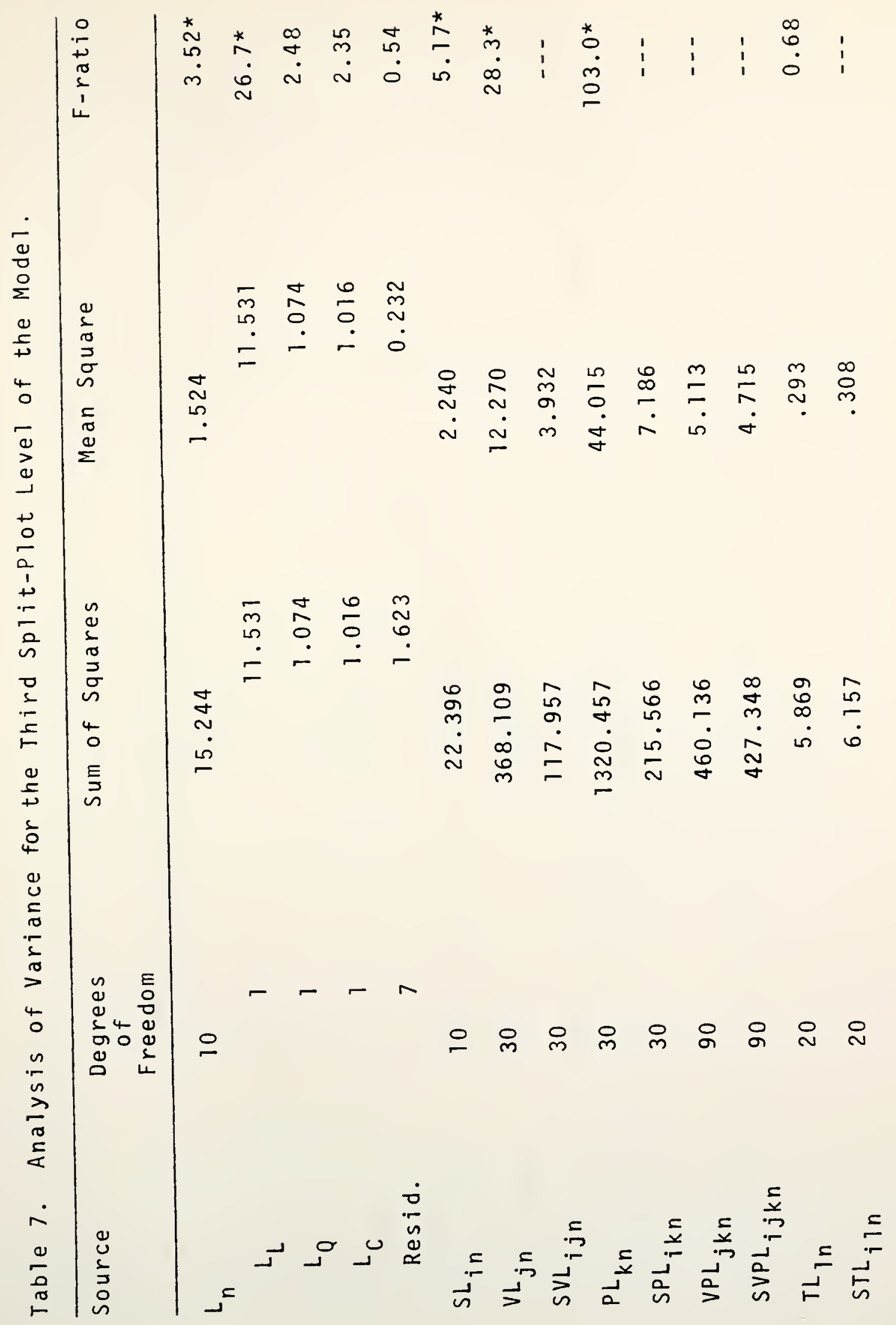




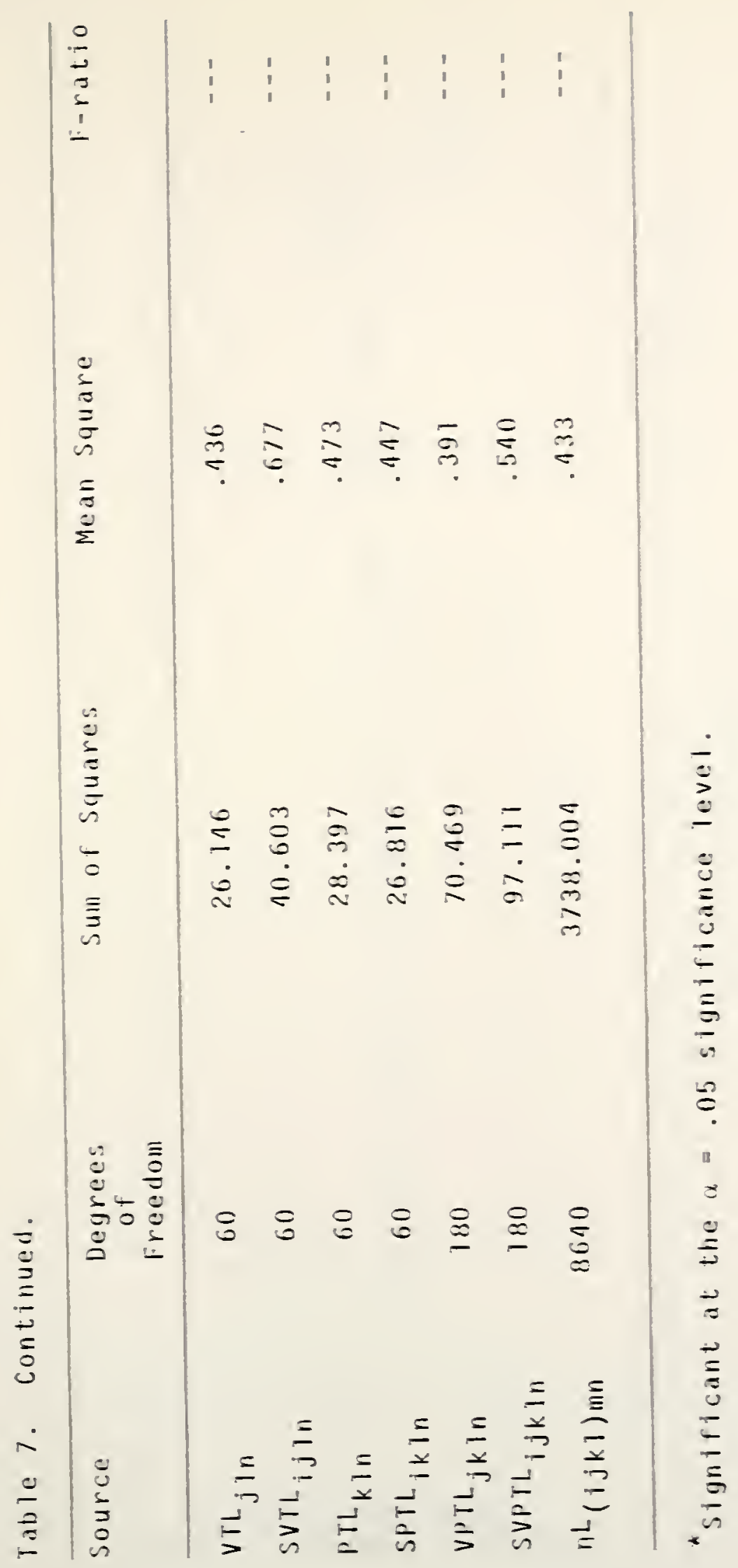




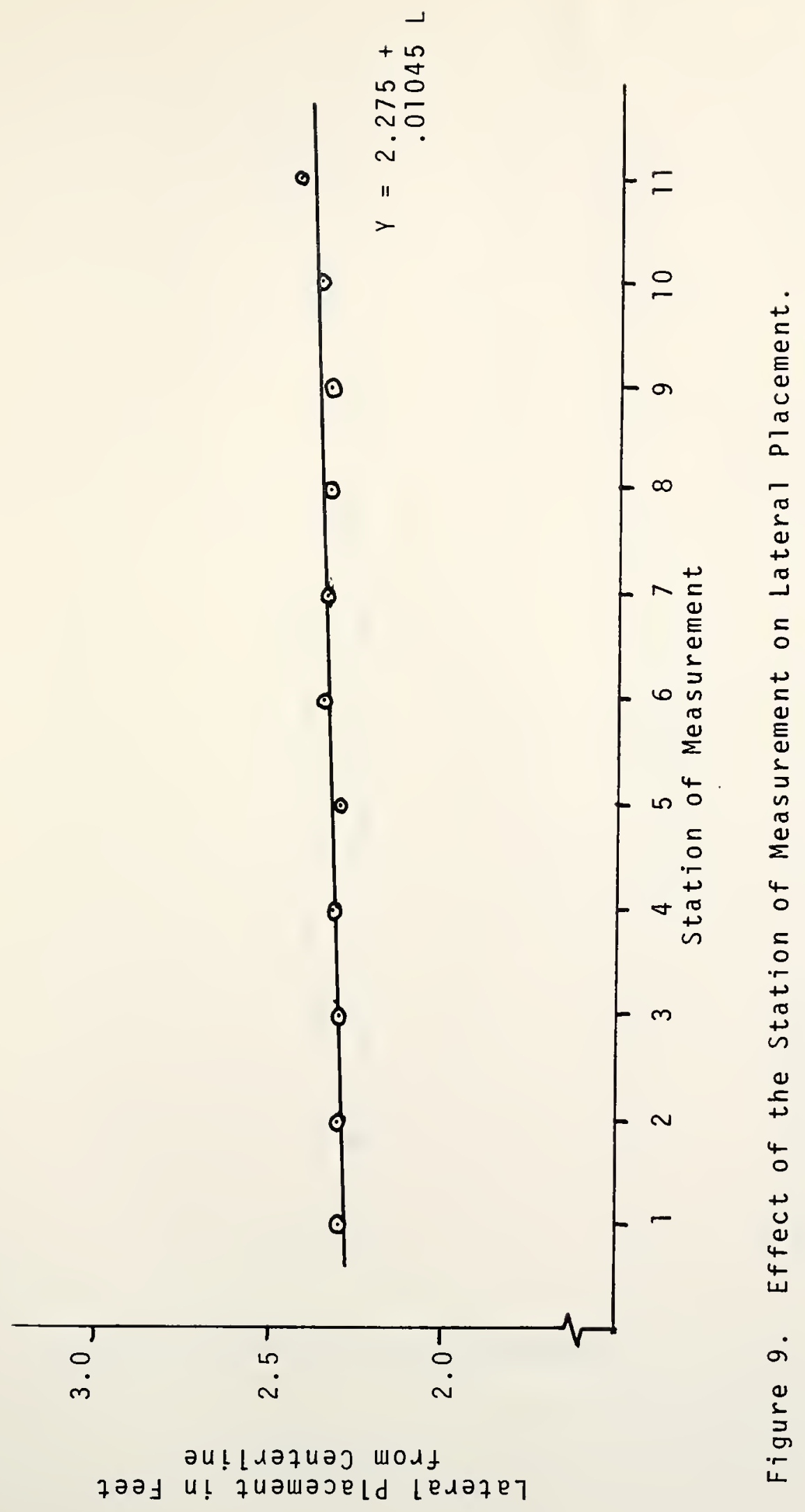




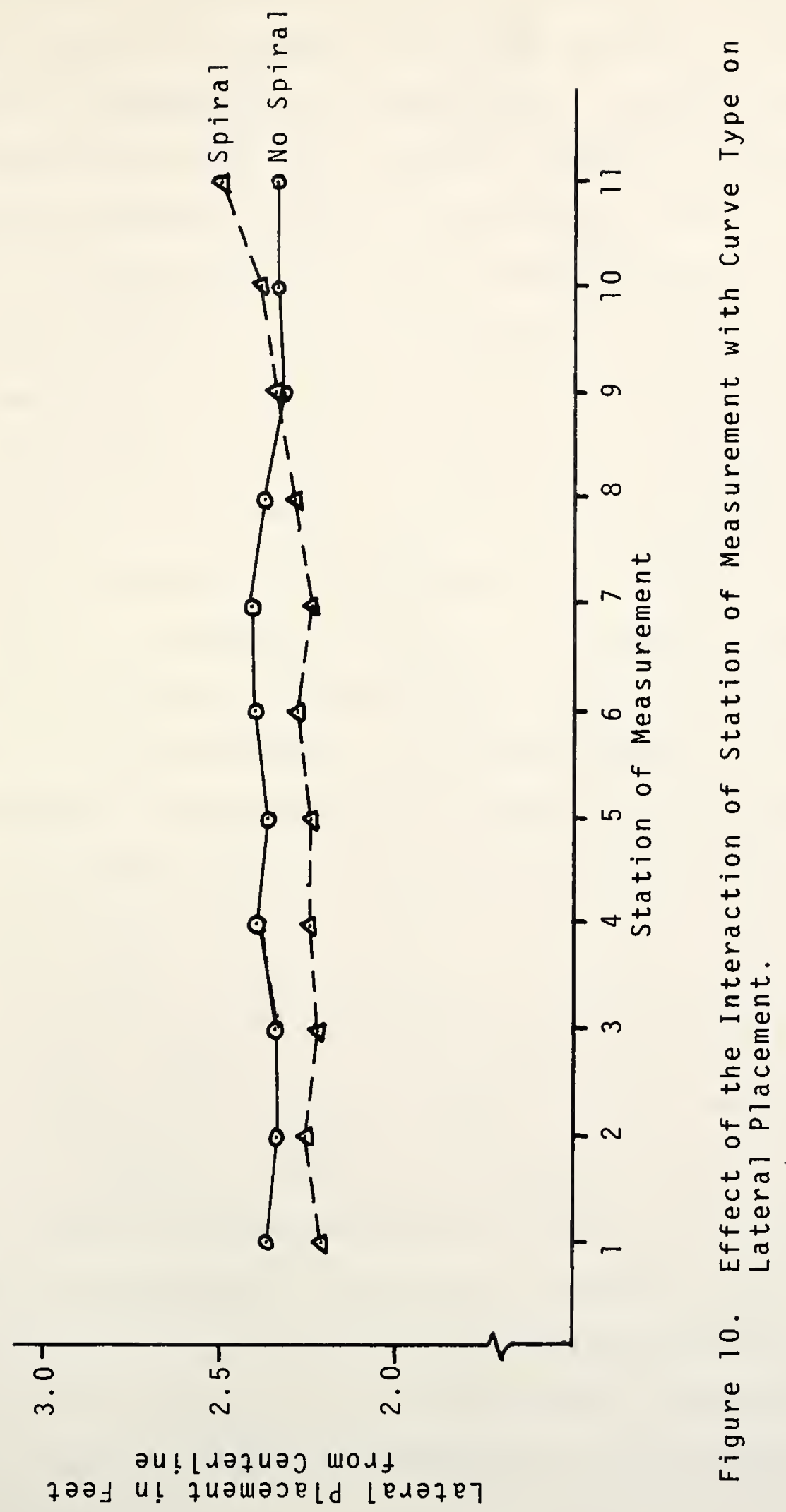


centerline as they move through the transition section, whereas vehicles on unspiraled curves remain at a nearly constant distance from the centerline. Assuming that the best path for a vehicle to follow is one which remains at a constant distance from the centerline, a vehicle tends to follow an unspiraled curve better than a spiraled curve for the curves studied in this investigation. This interaction provides the basic relationship to test the hypothesis that spiraled and unspiraled curves are similar, because the vehicle path shows which type of curve is best followed.

The interaction of curve group with station of measurement (VL) is presented in Figure 11. Although a systematic pattern of lateral placements was expected for this interaction, no relationship of the vehicle paths for the four curve groups is discernible. A further numerical analysis was not performed because no reason is apparent for the difference in paths.

In a graph of the interaction of curve position with station (PL) in Figure 12, the change in lateral placement on the roadway for positions $B$ and $C$ is from stations 4 to 8 , or about $200 \mathrm{ft}$. However, at positions $A$ and $D$ the transition length can not be determined because the average placement of vehicles on position $A$ increases with increasing stations while the path of vehicles on position $D$ fluctuates over the length of the study section. The expected types of vehicle paths are exhibited by the vehicles for positions $B$ and $C$. 


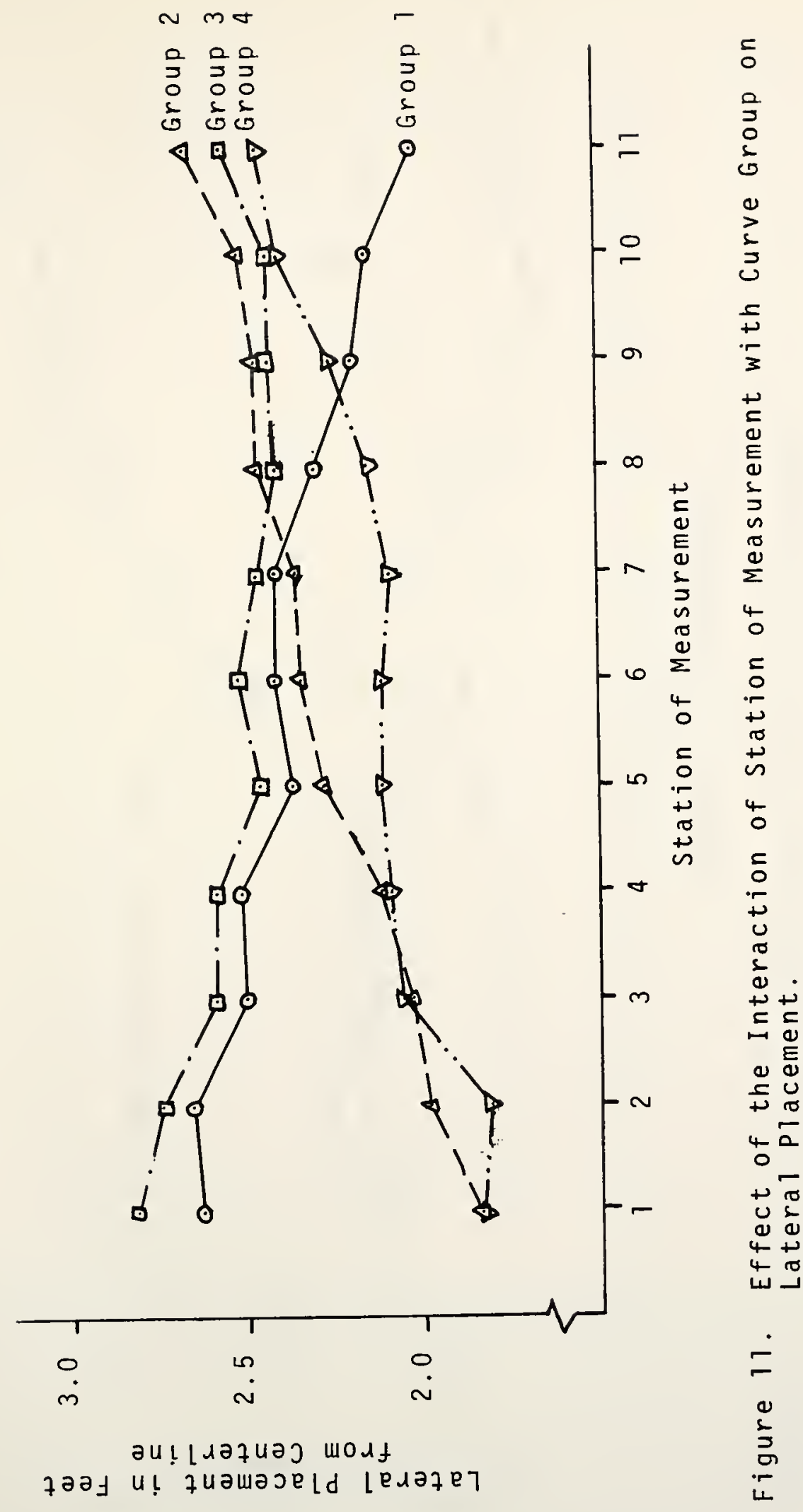




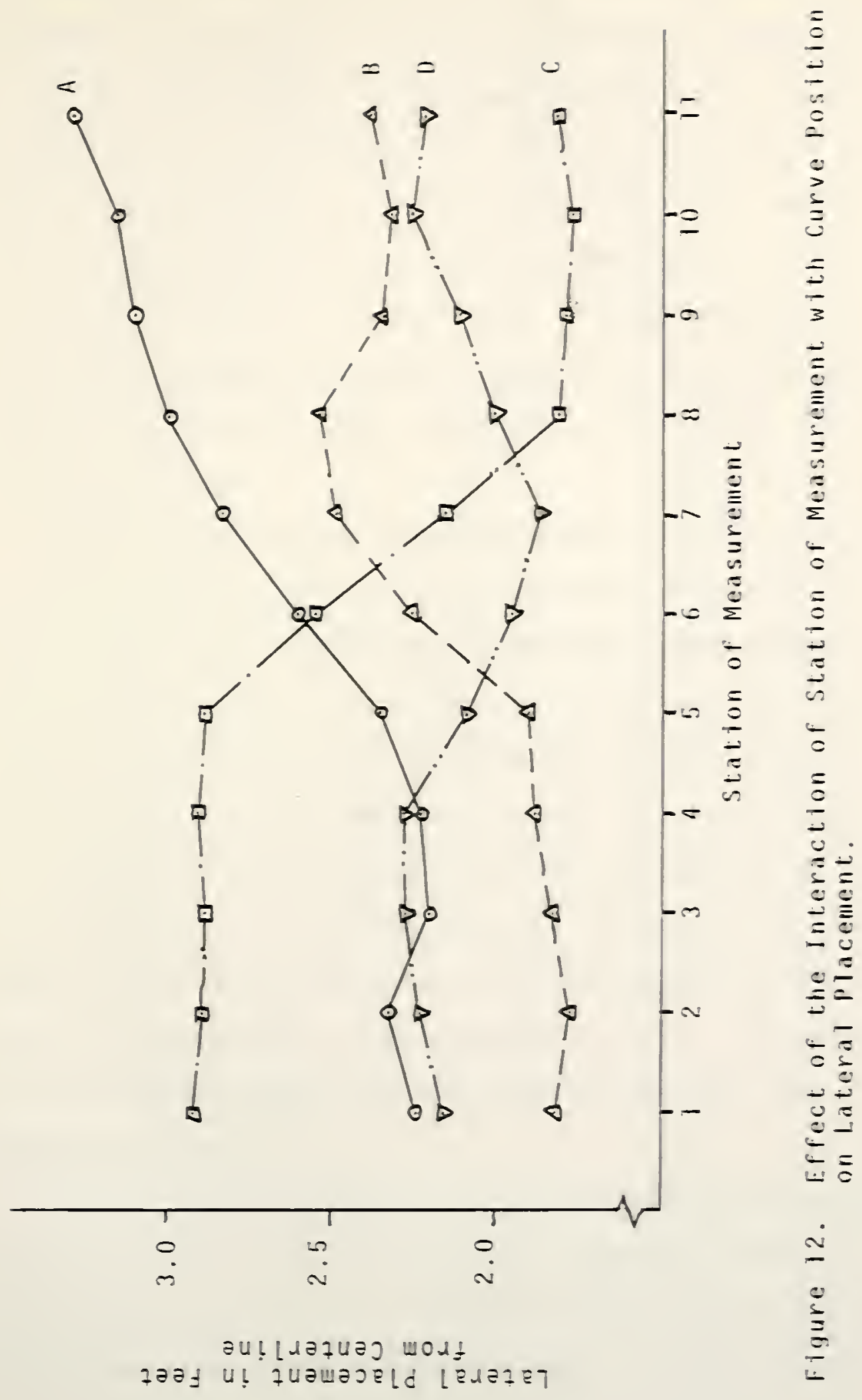


Several terms in the model were not found to be statistically significant, and the importance of these terms can not be overlooked. As discussed previously, several interactions of curve type with other variables were statistically significant, indicating differences among the values of the interaction. However, the type of curve (S) was not significant in this stuay. Without considering any other factors, the two types of curves do not differently affect the average lateral placement of a vehicle on a twolane, rural road.

The interactions of curve type with vehicle type (ST) and curve position (SP) also are not significant in this study. There are no differences between spiraled and unspiraled curves on each vehicle type, and the average vehicle lateral placement on each curve position does not vary significantly for the two curve types. Figure 13, depicting the interaction of curve type and vehicle type shows why this interaction is not significant. Each vehicle type travels closer to the centerline of a spiraled curve than the centerline of an unspiraled curve by about $0.1 \mathrm{ft}$. The other non-significant interactions produce graphs with nondiverging curves.

The inclusion of spirals in horizontal curve design does affect the lateral placement of vehicles traveling through these curves in a different manner than vehicles passing through curves without spirals. A vehicle tends to 


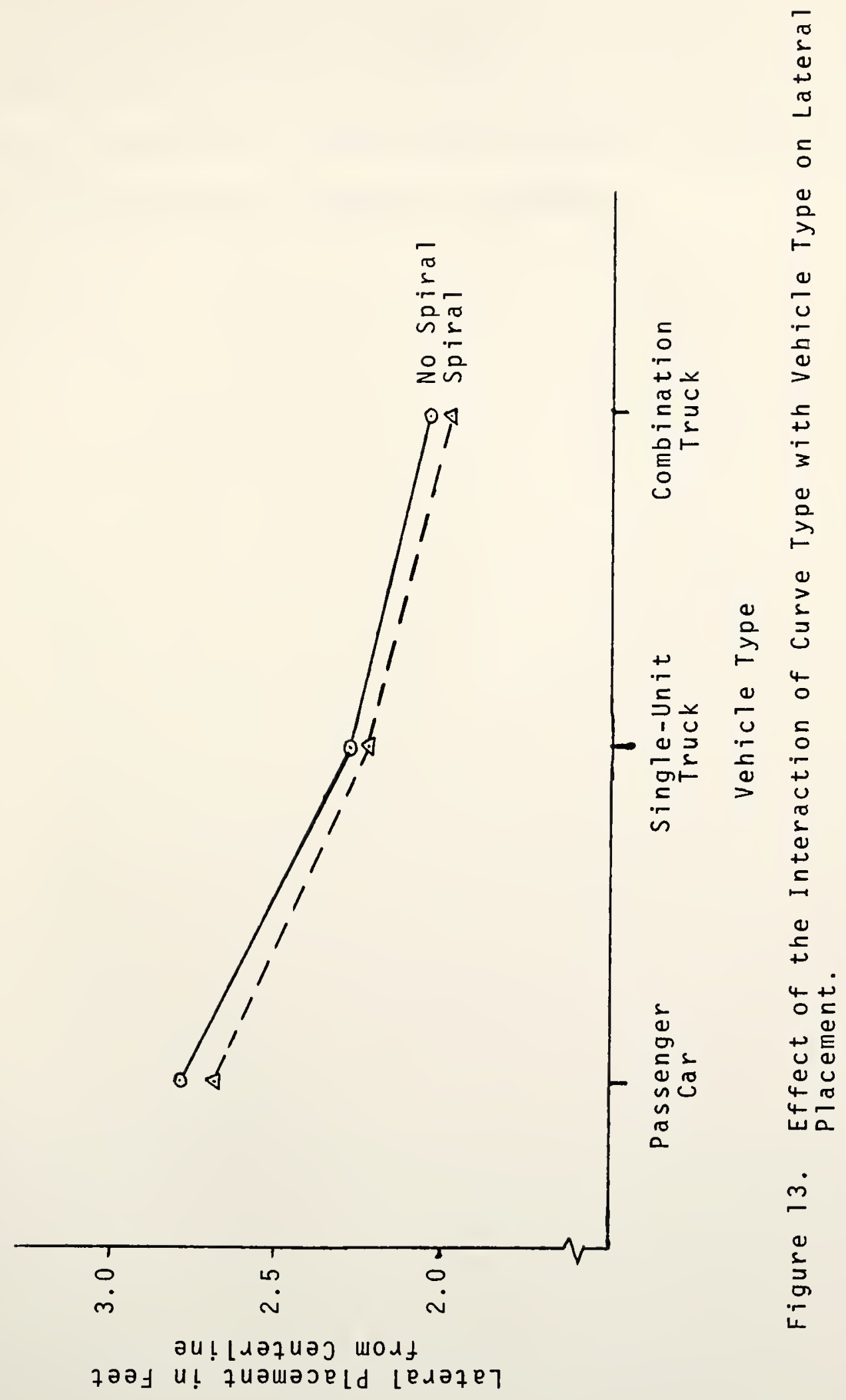


follow a non-spiraled curve at a more constant distance from the centerline than a spiraled curve. The sharpness of the curve affects the lateral placement of the vehicle and these placements are different for the various vehicle types considered. The paths of vehicles are different through the various curve positions, groups, and types. 


\section{CONCLUSIONS}

This research was conducted to determine the effect of transition curves on horizontal alinement. Although these findings are only valid for the curves studied, the following canclusions were developed about the lateral placement characteristics of vehicles on horizontal curves.

1. For horizontal curves of three to five degrees, the average lateral placement of a vehicle is not affected by the use of spiraled or non-spiraled curves, but the paths of vehicles are affected by these types of curve. Vehicles tend to follow such non-spiraled curves with a more constant lateral placement from the centerline than they do a spiraled curve.

2. Automobiles, single-unit trucks and truck combinations do not have the same lateral placement characteristics, and do not react in the same manner on the various curve positions for horizontal curves of three to five degrees. Truck combinations travel closer to the centerline, on the average than do automobiles or single-unit trucks.

3. The paths of vehicles are different through the various curve positions and for each curve group and curve type for horizontal curves of three to five degrees. 


\section{SUGGESTIONS FOR FURTHER RESEARCH}

In the conduct of this investigation, needed areas of research on geometric design have become apparent. The following items are suggested for further study.

1. To complement the analysis of the data collected in this investigation, the experiment should be repeated on curves similar to those used in this study to better estimate the error terms.

2. The range of the experiment was restricted by the lack of curves with properties required for data collection. Because sharper curves are needed to evaluate more fully the effect of spirals on driver behavior, a study should be conducted which includes a wider range of degrees of curve.

3. Because speed is an important variable in driver behavior, a study of the effects of spiraled and unspiraled curves on vehicle speed is recommended.

4. All data for this study were collected on two-lane, rural roads. Because a large portion of new road construction is four-lane divided highway, an investigation of the effects of spirals on these roads should be conducted. 
5. Further study of the paths of vehicles through each curve position and various degrees of curve is recommended to provide greater insight to an explanation of driver behavior on horizontal curves. 


\section{B I BL I OGRAPHY}




\section{B I BL I OGRAPHY}

1. Anderson, V. L., "Restriction Errors for Linear Models (An Aid to Develop Models for Designed Experiments)," Biometrics, Vol. 26, No. 2, June 1970, pp. 255-268.

2. Barnett, J., Transition Curves for Highways, U.S. Government Printing Office, Washington, 1940.

3. Bozivich, H., Bancroft, T. A., and Hartley, H. O., "Power of Analysis of Variance Test Procedures for Certain Incompletely SpecifiedModels, I," Annuls of Mathematical Statistics, Vol. 27, No. 4, December T956, pp. 1017-1043.

4. Gray, P. and Kauk, W., "Circular and Elongated Freeway Exit Loop Ramps," Traffic Engineering, Vo1. 38, No. 7, April 1968, pp. 16-T9.

5. Green, F. H., "Method for Recording Lateral Position of Vehicles," Proceedings, Highway Research Board, Vol. 26, 1946 , pp. 397-404.

6. Greenshields, B. D., "The Photographic Method of Studying Traffic Behavior," Proceedings, Highway Research Board, Vol. 13, 1933, pp. 382-399.

7. Hicks, C. R., Fundamental Concepts in the Design of Experiments, Holt, Rinehart, and Winston, Inc., New York, 1964 .

8. Highway Users Federation for Safety and Mobility, "Traffic Control and Roadway Elements--Their Relationship to Highway Safety (Revised)," Washington, 1971.

9. Keese, C. J. and Schleider, R. H., "Correlation of Design and Operational Characteristics of Expressways in Texas," Bulletin 170, Highway Research Board, 1958, pp. $1-23$.

10. Ostle, B., Statistics in Research, Second Edition, The Iowa State University Press, Ames, Iowa, 1963.

11. Overmyer, R. A., The Effect of Pavement Width on Road Usage, Unpublished Thesis, Purdue University, August T948. 
12. A Policy on Geometric Design of Rural Highways, Washington, 1966.

13. Pushkarev, B., "Esthetic Criteria in Freeway Design," Proceedings, Highway Research Board, Vo1. 41, 1962 , pp. 89-108.

14. Quimby, W. S., Traffic Speed and Lateral Placement Investigation at a Highway Bridge, Unpublished Thes is, Purdue University, February 1948 .

15. Smith, B. L. and Fogo, R. D., "Some Visual Aspects of Highway Design," Record 172, Highway Research Board, 1967, pp. 1-20.

16. Stonex, K. A. and Noble, C. M., "Curve Design and Tests on the Pennsylvania Turnpike," Proceedings, Highway Research Board, Vol. 20, 1940, pp.429-45T.

17. Taragin, A., "Driver Behavior as Related to Shoulder Type and Width on Two-Lane Highways," Bulletin 170, Highway Research Board, 1958, pp. 54-76.

18. Taragin, A., "Driver Performance on Horizontal Curves," Proceedings, Highway Research Board, Vol. 33, 1954, pp. 446-466.

19. Taragin, A., "Effect of Roadway Width on Traffic Operations," Proceedings, Highway Research Board, Vol. 24, 1944 , pp. 292-317.

20. Tharp, K. J. and Harr, M. E., "A Quantitative Evaluation of the Geometric Aspects of Highways," Record 83 , Highway Research Board, 1965, pp. 29-44. 
APPENDIX 


\section{APPENDIX}

\section{Partitioning the Sum of Squares of an Interaction}

A generalized method for partitioning the sum of squares of an interaction is presented to explain the method of calculating the contrasts presented in the text.

The formula for the computation of the sum of squares associated with a contrast is:

$$
c_{j}=\left(\sum_{i=1}^{t} b_{i j} T_{i}\right)^{2} / \sum_{i=1}^{t} n_{i} b_{i j}^{2} \text { * }
$$

where:

$$
\begin{aligned}
& c_{j} \quad=\text { sum of squares of the } j \text { th contrast, } \\
& t \quad=\text { number of levels of the variable, }
\end{aligned}
$$

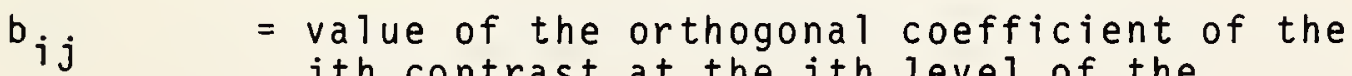

$$
\begin{aligned}
& j \text { th contrast at the } i \text { th level of the } \\
& \text { variable, } \\
& T_{i} \quad=\text { sum of the observations at the ith level } \\
& \text { of the variable, }
\end{aligned}
$$

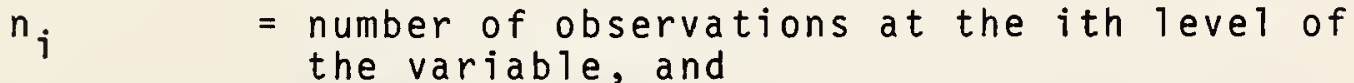

$$
\begin{aligned}
& \sum_{i=1}^{t} n_{i} b_{i j}=0 \text {. }
\end{aligned}
$$

*Ostle, B., Statistics in Research (Ames, Iowa: The Iowa State University Press, 1963), p. 306 (adapted). 
The following is an example of the calculation of the sum of squares for this type of contrast. The sum of squares for the contrast $V_{L 123}$ is desired. The data for the calculation are given in Table Al, along with the computations indicated by the formula. The sum of squares associated with this contrast is 36.020 .

The formula can also be applied to higher order interactions by accounting for the added dimensions. In the case of a two-way interaction, the formula becomes:

$$
c_{j}=\left(\sum_{k=1}^{u} \sum_{i=1}^{t} b_{i k j} T_{i k}\right)^{2} / \sum_{k=1}^{u} \sum_{i=1}^{t} n_{i k} b_{j k j}^{2}
$$

where:

$$
\begin{array}{ll}
c_{j} & =\text { sum of squares of the } j \text { th contrast, } \\
t & =\text { number of levels of the first variable, } \\
u & =\text { number of levels of the second variable, } \\
= & \text { value of the orthogonal coefficient of the } \\
& \text { jth contrast at the ith level of the first } \\
& \text { variable and the kth level of the second } \\
& \text { variable, } \\
= & \text { sum of the observations at the ith level } \\
& \text { of the first variable and the kth level } \\
& \text { of the second variable, } \\
= & \text { number of observations at the ith level } \\
T_{i k} & \text { of the first variable and the kth level } \\
& \text { of the second variable, } \\
n_{i k} & 0 \text {, and } \\
t & \\
\sum n_{i k} b_{i k j}=1 &
\end{array}
$$


Table Al. Calculation of the Sum of Squares of the Contrast $V_{L 123^{\circ}}$

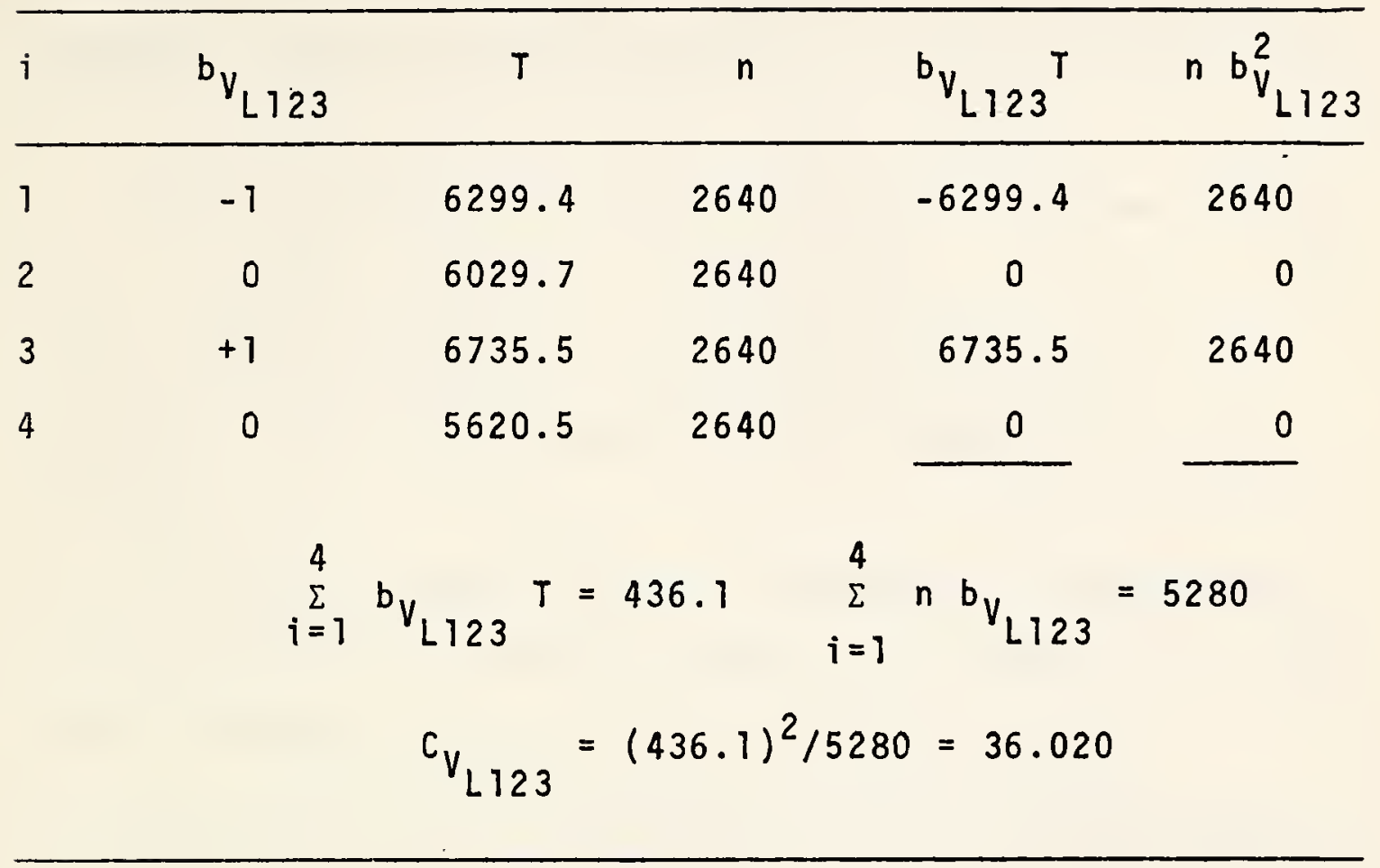

Table A2. Calculation of the Orthogonal Coefficients for Determining the Sum of Squares of the Contrast SV $L 123^{\circ}$

\begin{tabular}{c|cccc} 
& $v_{1}$ & $v_{2}$ & $v_{3}$ & $v_{4}$ \\
-1 & 0 & +1 & 0 \\
\cline { 3 - 5 }$S_{1}-1$ & +1 & 0 & -1 & 0 \\
$S_{2}+1$ & -1 & 0 & +1 & 0
\end{tabular}


The value of $b_{i k j}$ is obtained by the multiplication of the orthogonal coefficients of the variables in the desired contrast, that is, by multiplying $b_{i j}$ by $b_{k j}$ for each $i$ and k.

The calculation of the sum of squares for the contrast $S_{L 123}$ is given in Table $A 3$ using the data presented in that table. The computation of the coefficients is given in Table A2. The sum of squares for the contrast SV $L_{123}$ is 84.994 .

A further extension of the concept can be made to partition the sums of squares of three-way interactions. The formula becomes:

$$
c_{j}=\left(\sum_{1=1}^{v} \sum_{k=1}^{u} \sum_{i=1}^{t} b_{i k 1 j} T_{i k 1}\right)^{2}, \sum_{1=1}^{v} \sum_{k=1}^{u} \sum_{i=1}^{t} n_{i k 1} b_{i k 1 j}^{2}
$$

where:

$$
\begin{aligned}
c_{j} & =\text { sum of squares of the } j \text { th contrast, } \\
t & = \\
u & \text { number of levels of the first variable, } \\
v & \text { number of levels of the second variable, } \\
= & \text { number of levels of the third variable, } \\
= & \text { value of the orthogonal coefficient of the } \\
& \text { jth contrast at the ith level of the first } \\
& \text { variable, the kth level of the second } \\
& \text { variable, and the } 1 \text { th level of the third } \\
& \text { variable, } \\
= & \text { sum of the observations at the ith level } \\
& \text { of the first variable, the kth level of } \\
& \text { the second variable, and the } 1 \text { th level of } \\
& \text { the third variable, } \\
= & \text { number of observations at the ith level of } \\
& \text { the first variable, the kth level of the } \\
& \text { second variable, and the } 1 \text { th level of the } \\
& \text { third variable, }
\end{aligned}
$$




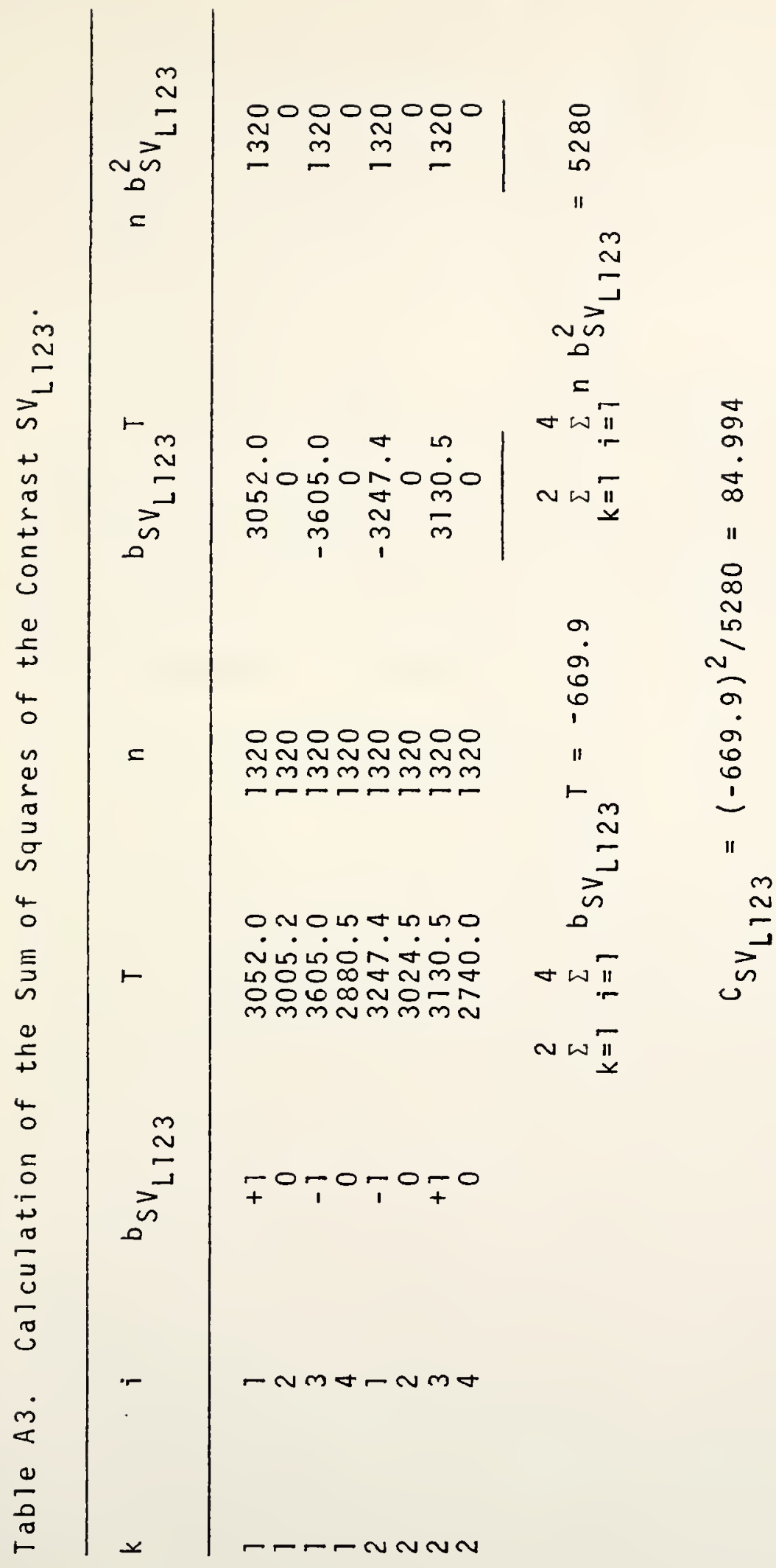




$$
\begin{aligned}
& \sum_{\substack{i=1 \\
u}}^{t} n_{i k l} b_{i k 1 j}=0, \\
& \sum_{k=1} n_{i k l} b_{i k 1 j}=0 \text {, and } \\
& \sum_{l=1} n_{i k l} b_{i k l j}=0 .
\end{aligned}
$$

The sum of squares of the contrast SV $L 123^{P} A C$ is calculated, as an example, in Table A5. The orthogonal coefficients are computed in Table A4, using the coefficients of $S_{L 123}$ calculated in Table A2. The resulting sum of squares of the contrast is 460.001 . 
73

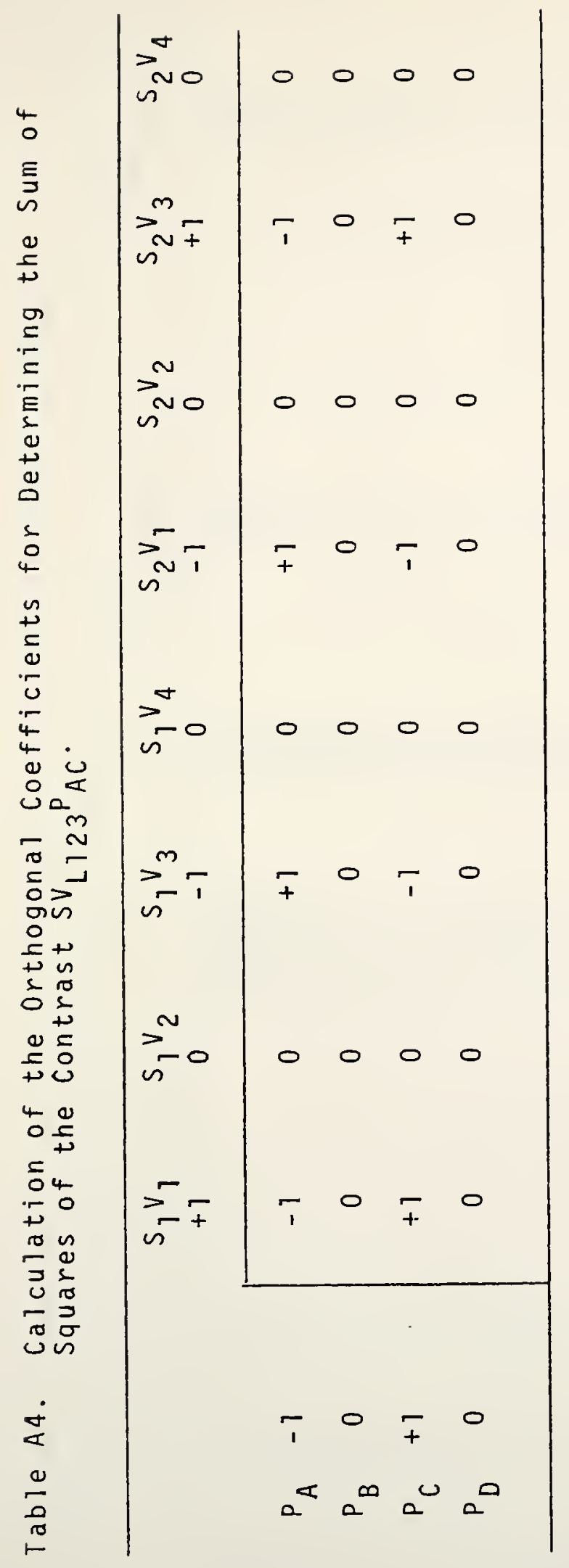




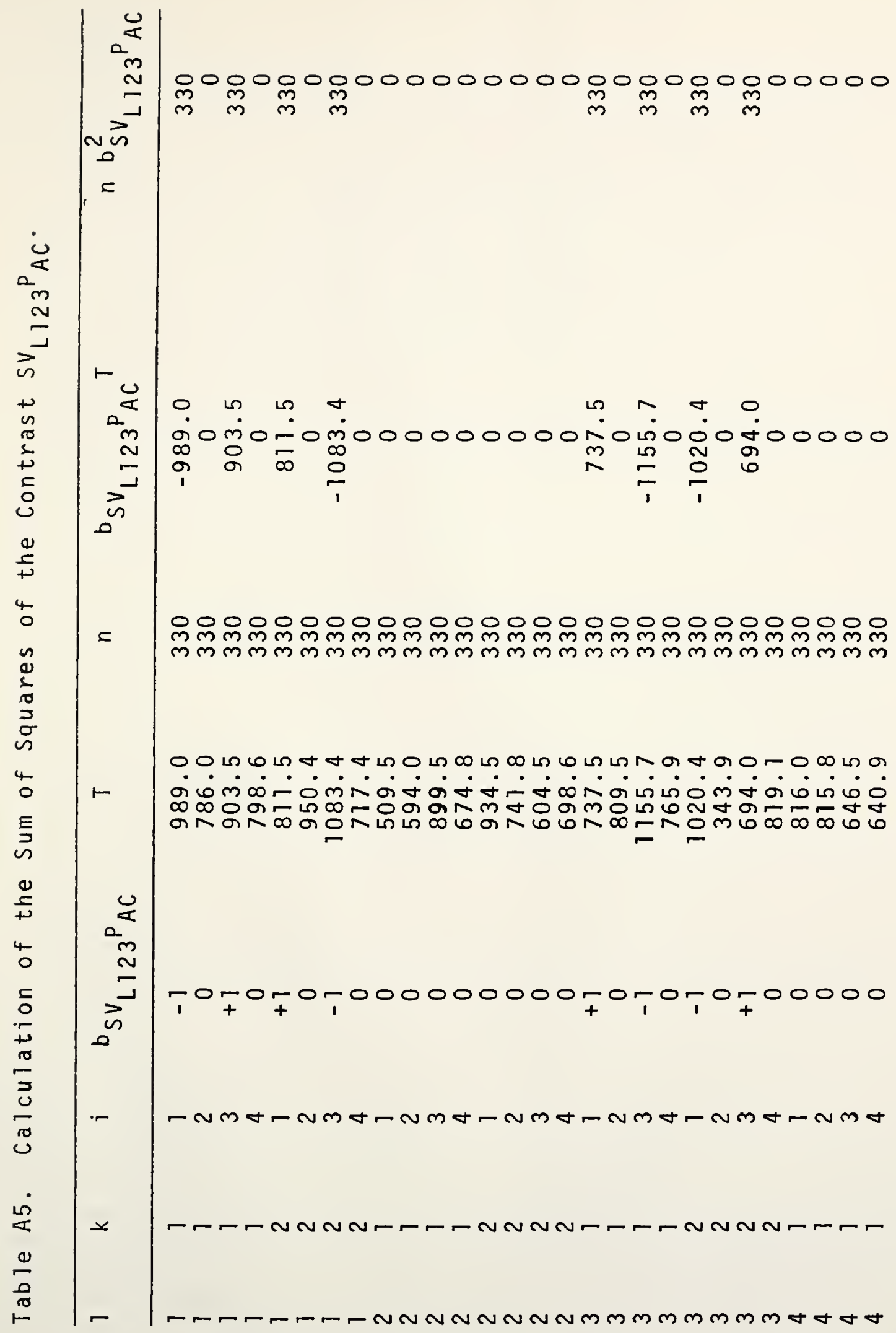




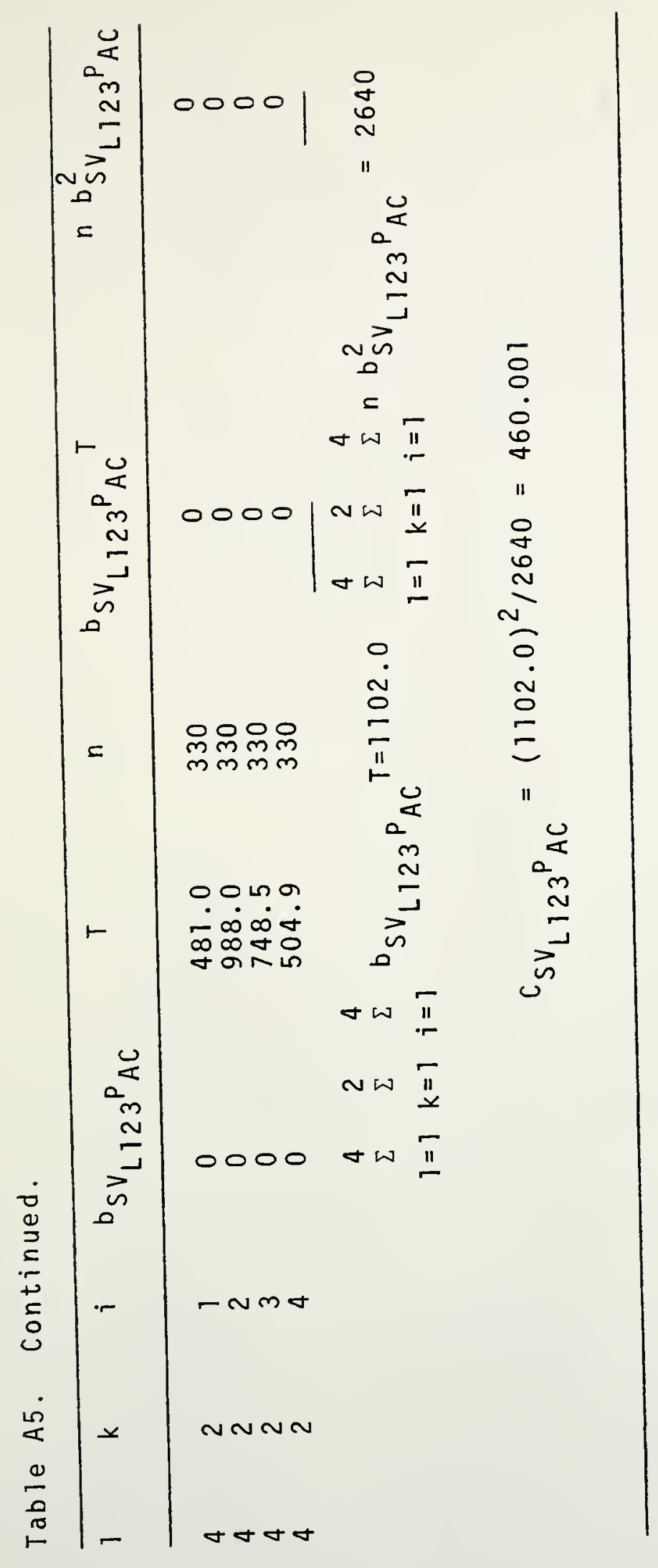



